\title{
Review of Odontoscelio Kieffer, 1905 (Platygastroidea, Scelionidae) with the description of two new species from India
}

\author{
Kamalanathan VEENAKUMARI ${ }^{1, *}$ \& Prashanth MOHANRAJ ${ }^{2}$ \\ ${ }_{1,2}^{1,2}$ ICAR - National Bureau of Agricultural Insect Resources, P.B. no. 2491, \\ Hebbal, Bengaluru, India 560024. \\ *Corresponding author: veenapmraj@gmail.com \\ 2Email: veenaprashi@rediffmail.com \\ ${ }^{1}$ urn:1sid:zoobank.org:author:39BB7D7D-0AA9-4E7C-97AD-CEEE9964552A \\ ${ }^{2}$ urn:1sid:zoobank.org:author:9C543AE3-039A-4A00-9599-9967CC73C017
}

\begin{abstract}
All species of Odontoscelio Kieffer, 1905 are imaged, with keys provided to all known males and females in this genus. Two new species, O. agnieleae sp. nov. and $O$. spinosus sp. nov., are described from India. The generic concept of the genus Odontoscelio is discussed. The presence of axillular spines differentiates this genus from other teleasines such as Dvivarnus Rajmohana \& Veenakumari, 2011, Gryonoides Dodd, 1920 and the Trimorus carus (Nixon, 1936) species group, which possess lateral mesoscutellar spines.
\end{abstract}

Keywords. Teleasinae, Carabidae, egg parasitoids.

Veenakumari K. \& Mohanraj P. 2021. Review of Odontoscelio Kieffer, 1905 (Platygastroidea, Scelionidae) with the description of two new species from India. European Journal of Taxonomy 739: 51-91.

https://doi.org/10.5852/ejt.2021.739.1267

\section{Introduction}

The subfamily Teleasinae in the family Scelionidae comprises 13 genera, of which four are represented in India: Trimorus Förster, 1856, Xenomerus Walker, 1836, Odontoscelio Kieffer, 1905, Trisacantha Ashmead, 1887 and Dvivarnus Rajmohana \& Veenakumari, 2011 (Johnson 1992; Mukerjee 1993; Veenakumari et al. 2011b). While the former two are species-rich, the latter two are represented by a mere handful of species worldwide.

Kieffer (1905) erected the genus Odontoscelio, with O. striatifrons Kieffer, 1905 as the type species, based on a male specimen collected from the island of Bolama in Guinea Bissau (formerly Portuguese Guinea) in West Africa. Odontoscelio occur in the Neotropical, Afrotropical and Oriental regions. Only eight species of Odontoscelio have been described in the world, of which seven are from Africa - O. apperti (Risbec, 1953), O. brevicephalus (Risbec, 1956), O. caelebs (Nixon, 1936), O. echion (Nixon, 1936), O. laticephalus (Risbec, 1950), O. pluto (Nixon, 1936) and O. striatifrons Kieffer - and the eighth, O. vikata Veenakumari \& Rajmohana, 2011, is the sole representative from India (Kieffer 1905; Nixon 1936; Risbec 1950, 1953, 1956; Masner 1976; Johnson 1992; Veenakumari et al. 2011a; Various contributors 2020). Odontoscelio apperti and O. caelebs were described based on females and the remaining six species were described based only on males. 
The species of the subfamily Teleasinae are egg parasitoids of Carabidae (Coleoptera), but the hosts of species of Odontoscelio, in particular, remain unknown (Masner 1976).

We here provide illustrations of type specimens for all species of Odontoscelio, including the two new species. Keys to the known males and females of all species of Odontoscelio are furnished. Three undescribed species from India, represented by males alone, are imaged for use in future studies.

\section{Material and methods}

Terminology for morphology follows Masner $(1976,1980)$ and Mikó et al. (2007, 2010) and for macroand microsculpture Harris (1979). All the specimens were collected using yellow pan traps (YPT), a Malaise trap (MT) or sweep nets (SN).

Specimens were mounted on card-point tips. The descriptions, measurements and imaging were carried out with a Leica M205A stereo microscope, with a $1 \times$ objective and a Leica DFC-500 digital camera with an LED ring light illuminator. The images were stacked using Leica Application Suite (LAS) software. All the measurements are taken as per Mikó et al. (2010). Widths of all metasomal tergites were taken anteriorly and lengths medially.

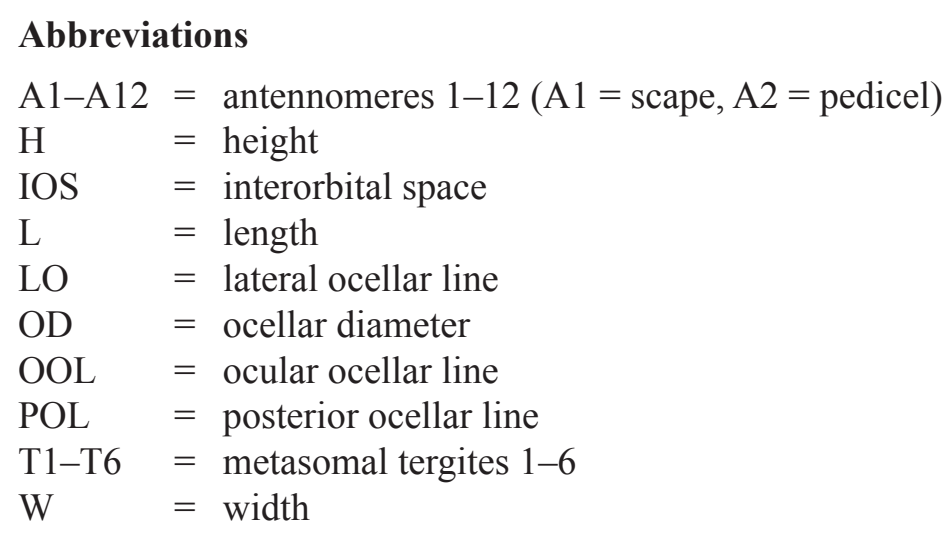

\section{Institutional abbreviations}

ICAR-NBAIR = ICAR - National Bureau of Agricultural Insect Resources (formerly National Bureau of Agriculturally Important Insects (ICAR-NBAII)), Bengaluru, India

MCSN = Museo Civico di Storia Naturale "Giacomo Doria", Genova, Italy

MNHN $\quad=$ Muséum national d'histoire naturelle, Paris, France

NHMUK = Natural History Museum, London, United Kingdom

The type specimens of all the new species are deposited at ICAR-NBAIR.

\section{Results}

Class Insecta Linnaeus, 1758

Order Hymenoptera Linnaeus, 1758

Superfamily Platygastroidea Naumann, 1991

Family Scelionidae Haliday, 1839

Subfamily Teleasinae Ashmead, 1902

Tribe Teleasini Ashmead, 1893

Genus Odontoscelio Kieffer, 1905

Odontoscelio Kieffer, 1905: 13 (type species: Odontoscelio striatifrons Kieffer, 1905).

Macrogryon Nixon, 1936: 116 (synonymized by Masner 1976). 


\section{Diagnosis}

The genus Odontoscelio is diagnosed by the following combination of character states: axillular spine elongate and posteriorly directed; eyes with dense, long setae; radicle very short; netrion narrow; T6 in females with two lateral spines and a medial lobe; very large, robust black species (Masner 1976).

\section{Description}

Large, robust, densely setose, black species, with coarse sculpture; antennae in shades of dark brown except light yellow to light brown A3 and A4 in females; radicle short, less than half length of interantennal process; A3 more than $2 \times$ length of A4 in females; clypeus wide with lateral corners pointed; eyes with dense bristles; mandible either tridentate or subtridentate (with median tooth shorter than upper and lower teeth); facial striae present; frons generally entirely carinate, sometimes with a medial smooth patch; central keel either present or absent; hyperoccipital carina absent; pronotum visible when viewed dorsally, sometimes with a short spine on pronotal shoulders; epomial carina present; notaulus absent; netrion present; femoral depression transversely carinate; mesoscutum and mesoscutellum coarsely sculptured, latter sometimes with a median keel; axillular spine elongate and posteriorly directed; metascutellum with a strong posteromedial spine; posterior propodeal projection present; metasoma spatulate; T1 sometimes with a horn; T1 and T2 longitudinally costate; T3 with varied sculpture; T6 in females with lateral teeth and a median lobe. Males with elongate, stout antennomeres, A4 and A5 shorter than A3; T3-T6 densely setose, with lateral patch.

\section{Remarks}

Masner (1976), in his revision of the world genera of Scelionidae, furnished a key to the genera of Teleasinae. Odontoscelio and Gryonoides Dodd, 1920 are diagnosed in this key by the presence of lateral mesoscutellar spines (sensu Masner 1976). Veenakumari et al. (2011b) described a third genus, Dvivarnus Rajmohana \& Veenakumari, also possessing lateral mesoscutellar spines. Talamas et al. (2016) included the Trimorus carus (Nixon, 1936) species group with this character state and provided a key for the three genera - Gryonoides, Dvivarnus and the Trimorus carus species group - all sharing lateral mesoscutellar spines. The lateral spines on the mesosoma in Odontoscelio have now been clarified to be elongations of the axillula, and they are hence axillular spines and not mesoscutellar spine as in Gryonoides, Dvivarnus and Trimorus carus. As of now there are four lineages in Teleasinae possessing lateral spines, one with an axillular spine and three with mesoscutellar spines.

Odontoscelio agnieleae Veenakumari sp. nov.

urn:1sid:zoobank.org:act:537CB22A-1229-4EE6-BD24-769208D50EA5

Figs $1-2$

\section{Diagnosis}

This species is closest to O. apperti, but can be differentiated from it by the following characters: presence of a horn on $\mathrm{T} 1, \mathrm{~A} 3$ and $\mathrm{A} 4$ subequal in length and $\mathrm{T} 3$ medially punctate; in $O$. apperti: T1 without horn, A3 more than $2 \times$ the length of A4, and T3 medially longitudinally costate on anterior half, smooth with setigerous punctae on posterior half.

\section{Etymology}

This species is named in honour of Dr Agnièle Touret-Alby, Curator, MNHN.

\section{Material examined}

\section{Holotype}

INDIA • ; Rajasthan, Udaipur, Maharana Pratap University of Agriculture and Technology (MPUAT); 24³6'02" N, 7344'21" E; alt. 583 m; 23 Sep. 2016; YPT; ICAR-NBAIR P3963. 


\section{Paratypes}

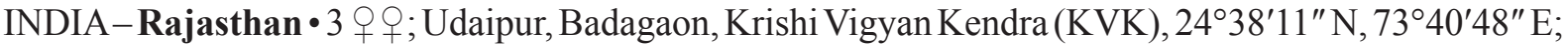
alt. 178 m; 24 Sep. 2016; YPT; ICAR-NBAIR P3964 to P3966 • 1 ते; same collection data as for

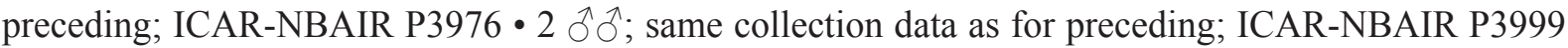

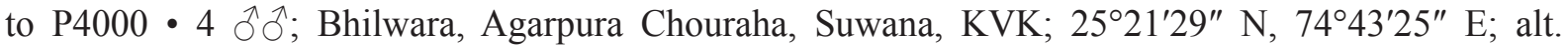
398 m; 28 Sep. 2016; YPT; ICAR-NBAIR P3971 to P3974. - Karnataka • 1 đ̇; Bengaluru, Hessaraghatta; $13^{\circ} 08^{\prime} 01^{\prime \prime}$ N, 77²9'27" E; alt. 859 m; 18 Jun. 2015; SN; ICAR-NBAIR P3968. - Madhya Pradesh • 2 o $^{\top}$; Bhopal, Central Institute of Agricultural Engineering (CIAE); $23^{\circ} 18^{\prime} 48^{\prime \prime} \mathrm{N}, 7^{\circ} 24^{\prime} 27^{\prime \prime} \mathrm{E}$; alt. 499 m; 15 Jun. 2011; YPT; ICAR-NBAIR P3969 to P3970.

\section{Description}

Female

Body LENGTH. $2.72(2.55-2.83) \mathrm{mm}, \mathrm{n}=4$.

Colour (Figs 1-2). Body black, tegula, legs, interantennal process and apical ends of lateral spines of mesoscutellum yellowish brown; anterior margin of lateral pronotal area brownish yellow; radicle, basal half of A1 and distal end of A2 yellowish brown, remainder of A1 and A2, including A3-A6, brownish black; clava darker than preceding antennomeres; mandibles yellowish brown.

HeAD (Figs 1,2A-C, E). Head setose, $1.21 \times$ as wide as high, $1.58 \times$ as high as long; IOS $0.74 \times$ head width, $1.9 \times$ eye length; $\mathrm{OOL}>\mathrm{POL}>\mathrm{LOL}$ in ratio of $18.5: 7.2: 2.5$; OOL $3.1 \times \mathrm{OD}$; eye $(\mathrm{L}: \mathrm{W}=27.7: 19.4)$ setose; frons anteriorly setigerous punctate, medially smooth; facial striae adjacent to medial smooth patch, decreasing in size as they progress towards centre; space between carinae smooth; interantennal process rectangular and rugose; vertex smooth with sparse punctae; ocelli not raised above surface of vertex; interocellar area smooth, sparsely setose; occiput smooth with sparse setigerous punctae; occipital carina foveate; facial striae prominent; gena smooth with sparse setigerous punctae and weak carinae; clypeus medially with a prominent longitudinal carina and transverse carinae basally, remainder smooth; length and width of antennomeres A1-A12 in ratio of $46.2: 7.2,7.8: 4.9,14.1: 6.3,13.9: 6.0$, $3.9: 5.0,3.8: 5.6,4.7: 7.9,6.9: 8.2,5.9: 8.7,5.6: 8.3,5.0: 7.9,8.8: 6.3$, respectively.

Mesosoma (Figs 1, 2C, E). Cervical pronotal area smooth; mesoscutum (L:W = 34.2:59.5) entirely areolate, areolae sparse medially; lateral pronotal area dorsally areolate, pronotal suprahumeral sulcus and pronotal cervical sulcus foveate, remainder smooth; netrion unevenly foveate; dorsal mesopleuron with a small rugose patch beneath tegula; mesopleural pit distinct; speculum with transverse carinae; mesepimeral sulcus foveate except in ventral $1 / 3$; femoral depression posteroventrally with elongate depressions; anteroventral mesopleuron areolate, setose; postacetabular sulcus indicated as a furrow; metapleuron anteriorly setose, with metapleural sulcus and posterodorsal metapleural sulcus foveate; ventral half of metapleuron areolate, setose; posterior margin of metapleuron with a wide spine; mesoscutellum $(\mathrm{L}: \mathrm{W}=18.1: 41.0)$ with a row of cells on anterior margin, remainder areolate, with a weak median keel; metascutellum foveate and posteromedially with a spine, metanotal trough foveate; lateral propodeal area with uneven depressions, with a short spine anterolaterally and an outward bending long spine posterolaterally. Fore wing $(\mathrm{L}: \mathrm{W}=160.5: 52.6)$ and hind wing $(\mathrm{L}: \mathrm{W}=132.9: 29.1)$ hyaline.

Metasoma (Fig. 1A-B). L:W = 126.7:66.7; T1 anteriorly smooth, with a short, smooth horn anteromedially, remainder longitudinally costate with weak foveae between costae; T2 with weak basal foveae, longitudinally costate, space between costae predominantly smooth; T3 medially punctate, submedially and sublaterally longitudinally costate with foveae between costae, laterally and posteriorly smooth; remaining tergites smooth with setigerous punctae; T1-T3 laterally setose, remaining tergites evenly setose; length and width of tergites T1-T6 in ratio of $25.9: 20.6,26.8: 26.4,45.8: 59.8,14.5: 62.1$, $6.0: 42.6,7.6: 17.7$, respectively. 


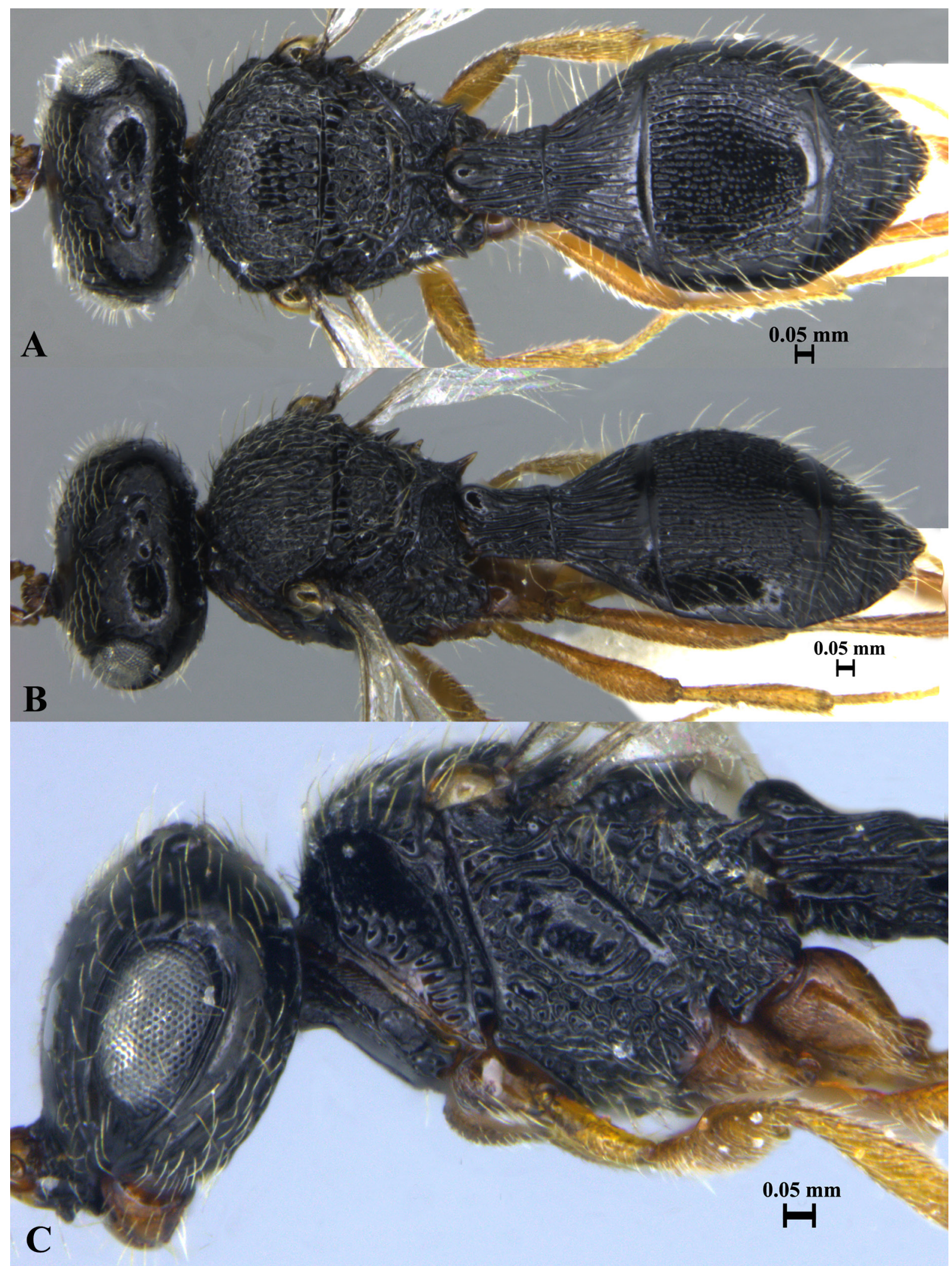

Fig. 1. Odontoscelio agnieleae sp. nov. Holotype, $q$ (ICAR-NBAIR P3963). A. Habitus (dorsal view). B. Habitus, showing axillular spines. C. Head and pleuron. 


\section{Male}

Body LeNGTH. $2.61(2.48-2.85) \mathrm{mm}, \mathrm{n}=8$.

Similar to female; length of antennomeres A1-A12 in ratio of $31.4: 7.8,4.2: 5.8,21.5: 6.6,20.3: 5.4$, $19.7: 6.5,22.3: 5.5,21.3: 6.2,20.5: 6.6,21.2: 6.2,20.1: 5.8,20.2: 5.7,21.6: 5.3$, respectively (Fig. 2F).

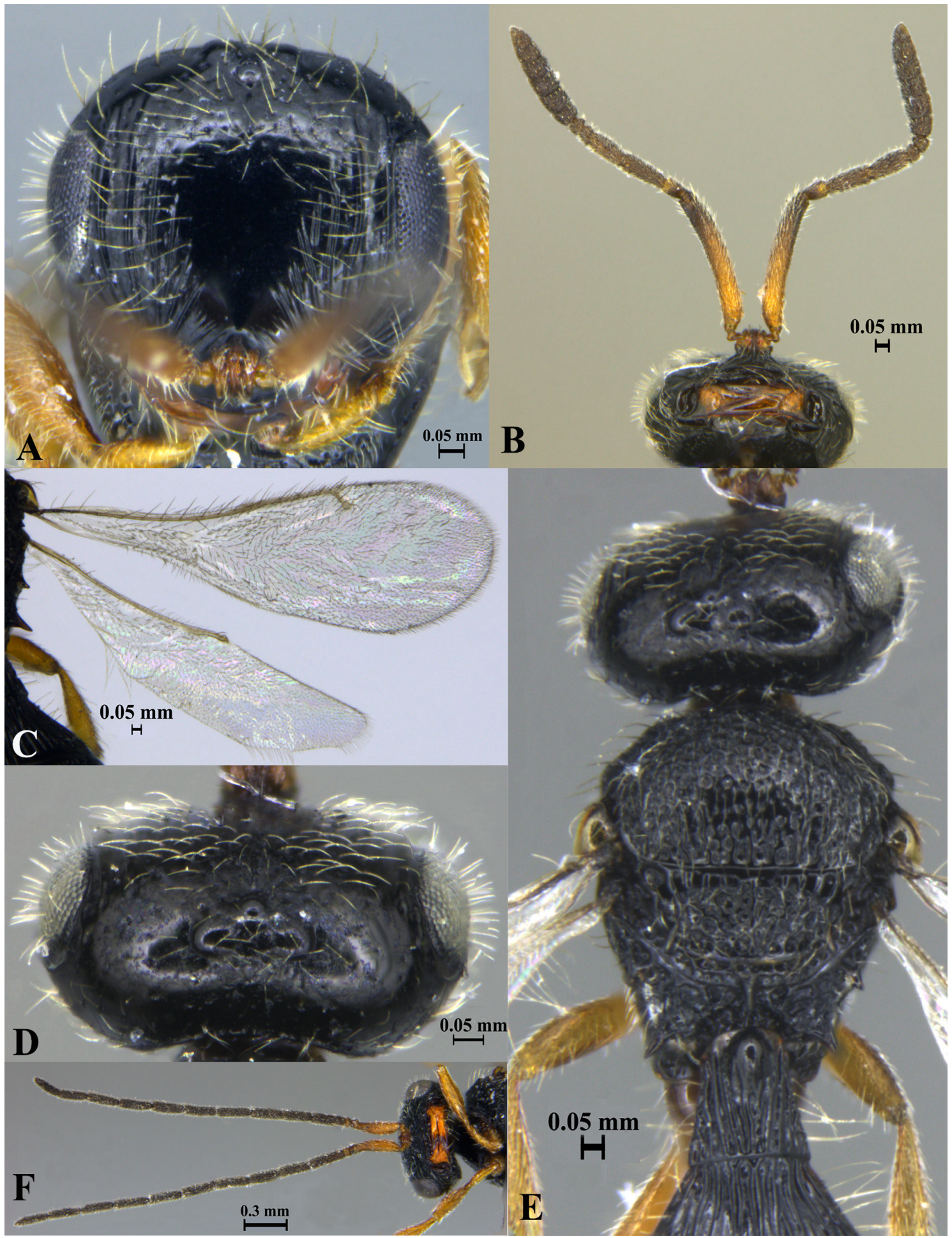

Fig. 2. Odontoscelio agnieleae sp. nov. A-E. Holotype, $q$ (ICAR-NBAIR P3963). A. Frons. B. Antennae. C. Wings. D. Vertex. E. Head and mesonotum. F. Paratype, ô (ICAR-NBAIR P3968), antennae. 
Odontoscelio spinosus Veenakumari sp. nov. urn:1sid:zoobank:org:act:909052D7-7052-45E0-85E2-C970C0CD4EF8

Figs $3-4$

\section{Diagnosis}

This species is very distinct because of the presence of semicircular carinae on the frons and 11 spines on mesosoma.

\section{Etymology}

This species is named 'spinosus' indicative of the 11 spines present on the mesosoma.

\section{Material examined}

\section{Holotype}

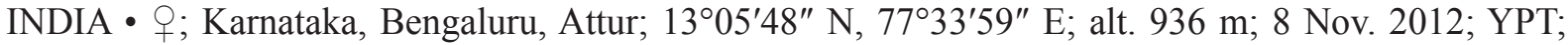
ICAR-NBAIR P3960.

\section{Description}

Female

BODY LENGTH. $4.78 \mathrm{~mm}, \mathrm{n}=1$.

Colour (Figs 3-4). Body predominantly black; tegula and legs brown; radicle and A2-A4 brown, A5A6 brownish black, remaining antennomeres black; mandible dark brown.

Head (Figs 3, 4A-C, E-G). Densely setose, $1.26 \times$ as wide as high, $1.38 \times$ as high as long; IOS $0.59 \times$ head width, subequal to eye length; OOL $>$ POL $>$ LOL in ratio of $23.8: 18.5: 7.3$; OOL $2.74 \times$ OD; eye $(\mathrm{L}: \mathrm{W}=71.6: 30.4)$ setose; frons beneath anterior ocellus with discontinuous semicircular carinae except for continuous ones above interantennal process; central keel absent; interantennal process rectangular and rugose; vertex and occiput areolate with very long setae; ocelli not raised above surface of vertex; interocellar area weakly rugose with an uneven carina between posterior ocelli; occipital carina foveate; facial striae prominent; gena longitudinally carinate, interspersed with sparse areolae; A1 with dense setae; length and width of antennomeres A1-A12 in ratio of $72.3: 12.5,10.0: 8.8,29.1: 11.6,15.5: 11.9$, $7.3: 11.1,8.3: 11.2,8.8: 15.2,10.5: 16.4,9.5: 10.3,9.8: 15.7,11.8: 14.7,9.1: 11.9$, respectively.

Mesosoma (Figs 3A-B, 4A-D, F). Cervical pronotal area transversely carinate; mesoscutum (L:W = $72.3: 117.2)$ densely setose, anteriorly areolate, posteriorly longitudinally carinate, interspersed with sparse uneven areolae; anterolateral margin of mesoscutum extending as a short spine above tegula; pronotum laterally with a wide spine, visible when viewed dorsally; lateral pronotal area transversely carinate with an areolate patch dorsally and posteriorly; netrion foveate; mesopleuron with distinct mesopleural pit; speculum with transverse carinae; mesepimeral sulcus not foveate, femoral depression ventral to mesopleural pit with transverse carinae on posterior margin extending $2 / 3$ width of mesopleuron, carinae progressively reduced in size ventrad; anterior episternum with intricate sculpture; mesopleuron ventrally with intricate sculpture interspersed with foveae, densely setose; postacetabular sulcus indicated as a furrow; metapleuron dorsally with intricate sculpture, ventrally foveate with dense setae and with a wide spine on posterior margin; scutoscutellar sulcus foveate laterally; mesoscutellum $(\mathrm{L}: \mathrm{W}=36.0: 73.0)$ areolate interspersed with carinae, densely setose, medial longitudinal keel distinct; metascutellum foveate with posteromedial spine, metanotal trough foveate; lateral propodeal area laterally densely setose, remainder longitudinally carinate and with a spine on anterolateral margin; posterolateral margin of lateral propodeal area curving inwards as a spine. Fore wing $(\mathrm{L}: \mathrm{W}=240.9: 68.3)$ infuscate; hind wing $(\mathrm{L}: \mathrm{W}=200.0: 52.40)$ hyaline. 


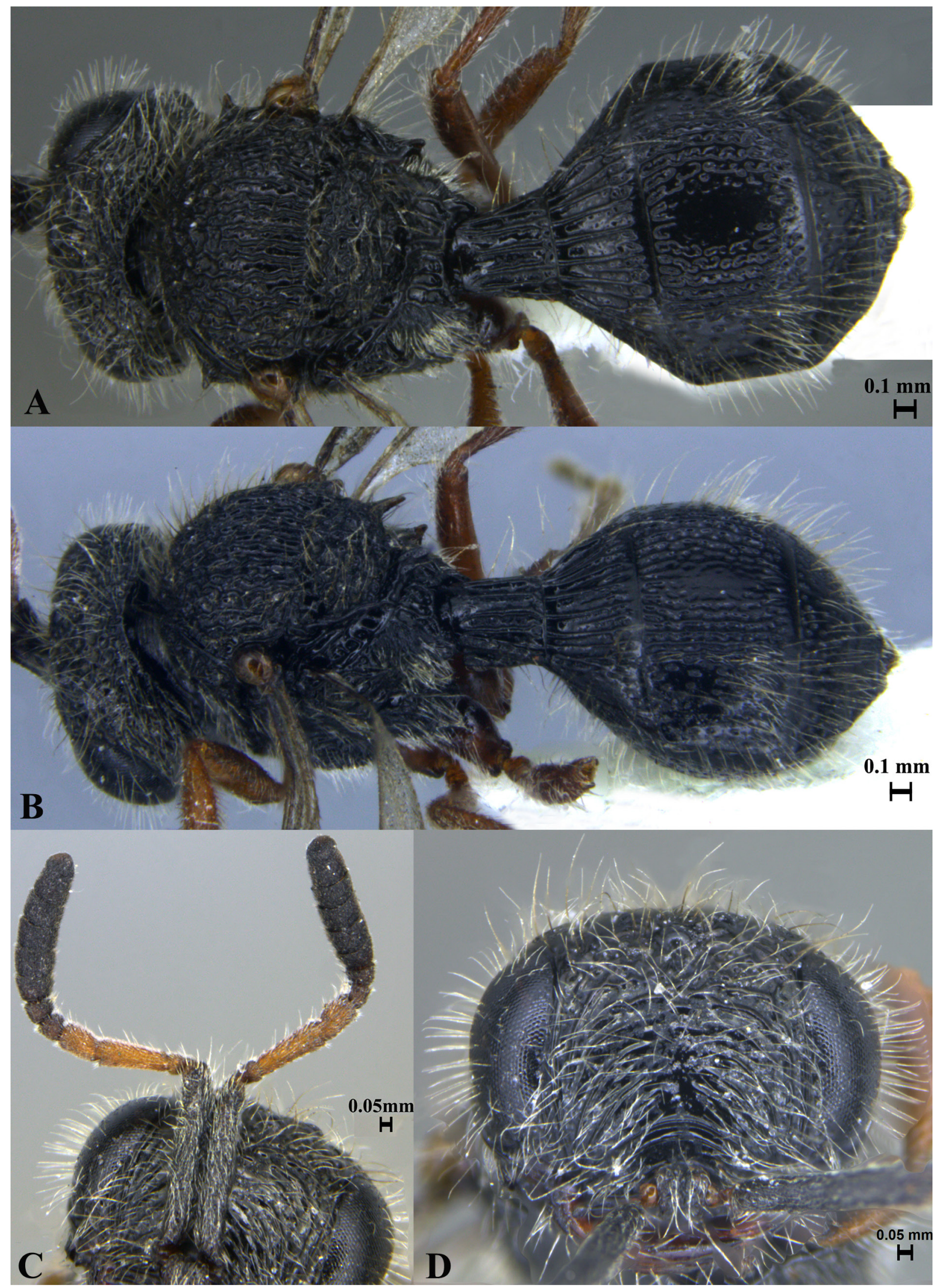

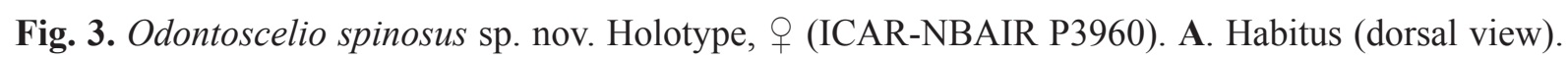
B. Habitus, showing axillular spines. C. Antennae. D. Frons. 
Metasoma (Fig. 3A-B). L:W = 203.2:143.0; densely setose; T1 anteromedially smooth, longitudinally costate, space between costae weakly foveate; T2 longitudinally costate with weak foveae between costae, an additional row of foveae present posteriorly followed by a posteromedial smooth patch; T3 medially smooth, sub medially unevenly foveate followed by longitudinal rows of uneven costae, space between costae foveate; T3 sublaterally and laterally smooth with setigerous punctae; remaining tergites smooth with setigerous punctae; T1 and T2 with sparse setae laterally, T3 densely setose posterosublaterally; length and width of tergites T1-T6 in ratio of $43.4: 37.4,42.1: 52.9,72.2: 142.6,22.7: 141.2,14.7: 87.2$, $6.8: 23.1$, respectively.

Male

Unknown.

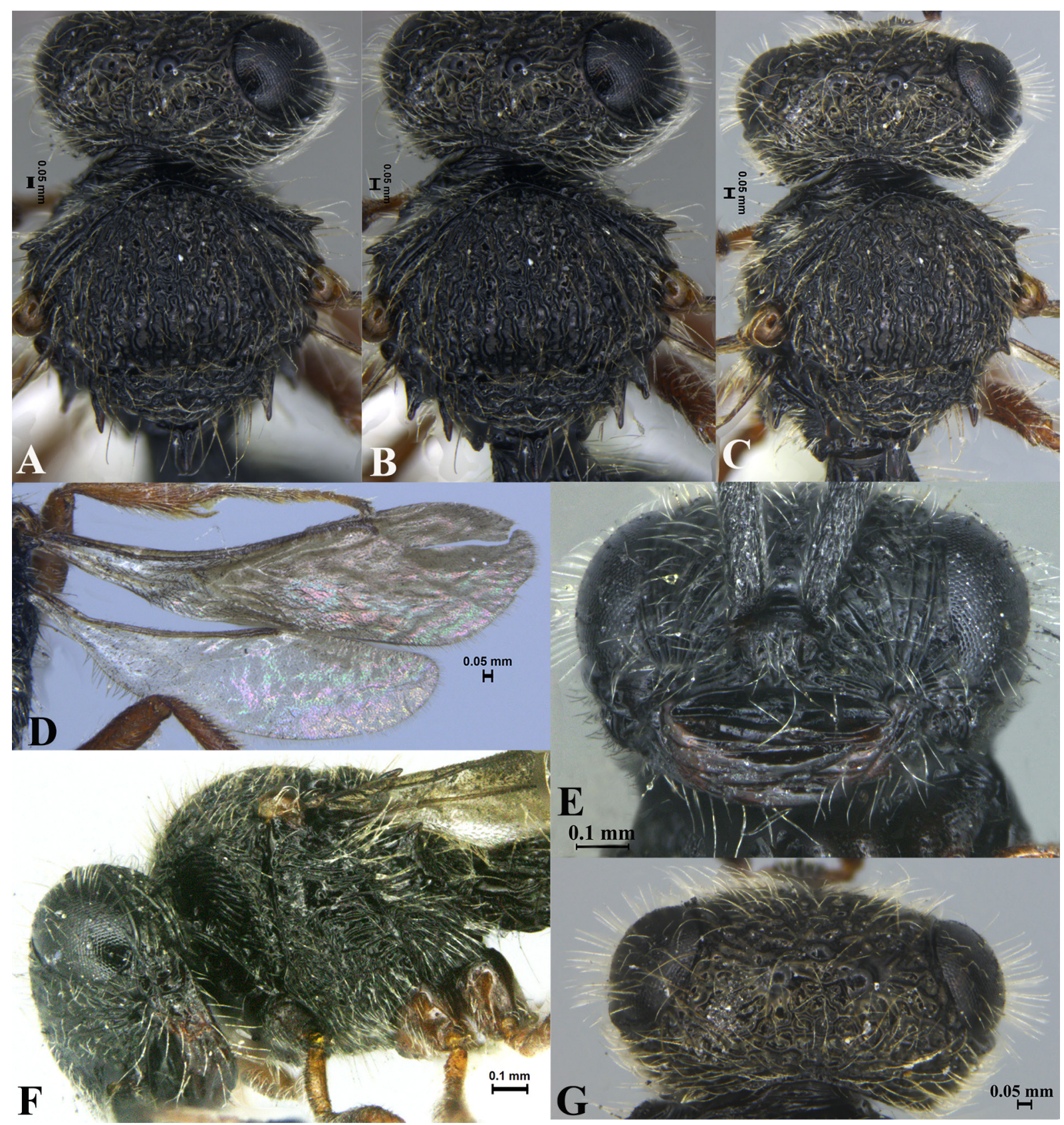

Fig. 4. Odontoscelio spinosus sp. nov. Holotype, ( (ICAR-NBAIR P3960). A-C. Mesoscutum showing axillular spines at different angles. D. Wings. E. Facial striae. F. Head and pleuron. G. Vertex. 
Odontoscelio apperti (Risbec, 1953)

Figs 5-6

Dichoteleas Apperti [sic] Risbec, 1953: 569, fig. 5 (holotype,, , MNHN).

Odontoscelio apperti - Masner 1976: 72 (transferred from Dichoteleas).

\section{Material examined}

Holotype (images only)

SENEGAL • +; Bambey [M'Bambey]; J. Appert leg.; MNHN EY25668.

\section{Redescription}

\section{Female}

BODY LENGTH. $5.8 \mathrm{~mm}$.

Colour (Figs 5, 6A-D). Body predominantly black; tegula, interantennal process, legs and apical ends of spines brown; A1 reddish brown, A2-A4 yellowish brown, remaining antennomeres blackish brown.

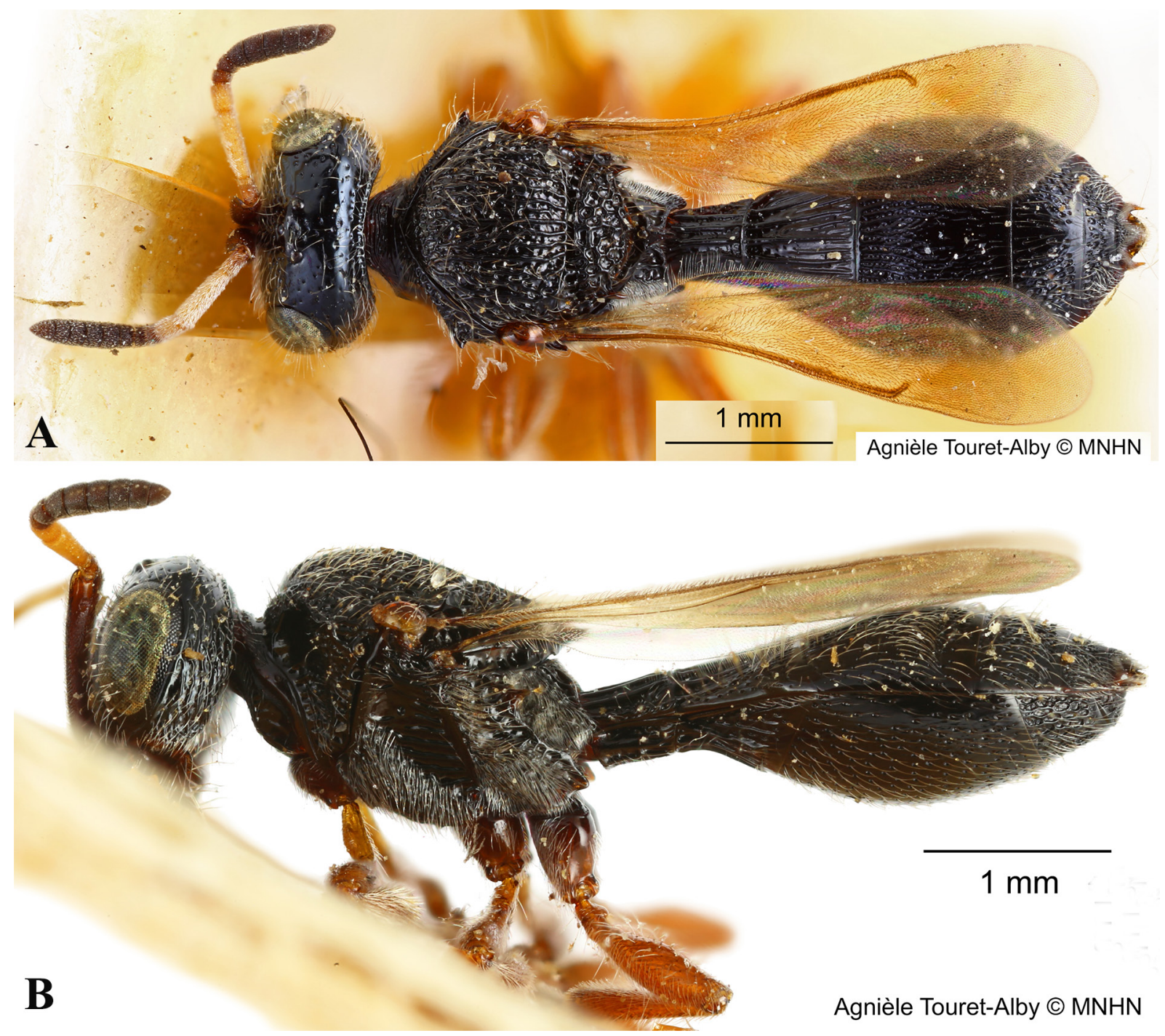

Fig. 5. Odontoscelio apperti (Risbec, 1953). Holotype,, (MNHN EY25668). A. Habitus (dorsal view). B. Habitus (lateral view). Photos: Agnièle Touret-Alby ${ }^{\circ}$, MNHN. 
Head (Figs 5, 6A, C-D). Head setose, $1.16 \times$ as wide as high, $1.9 \times$ as high as long; IOS $0.80 \times$ head width, subequal to eye length; $\mathrm{OOL}>\mathrm{POL}>\mathrm{LOL}$ in ratio of $27: 24: 12$; OOL $3.3 \times \mathrm{OD}$; eye $(\mathrm{L}: \mathrm{W}=78: 39)$ setose; frons entirely smooth with setigerous punctae except for sparse longitudinal carinae laterally towards orbits; vertex, interocellar area and occiput smooth with sparse setigerous punctae; ocelli raised above surface of vertex; occipital carina foveate; setae dense on temples; gena with longitudinal striae interspersed with setigerous punctae; length and width of antennomeres A1-A12 in ratio of 97.7:11.6,

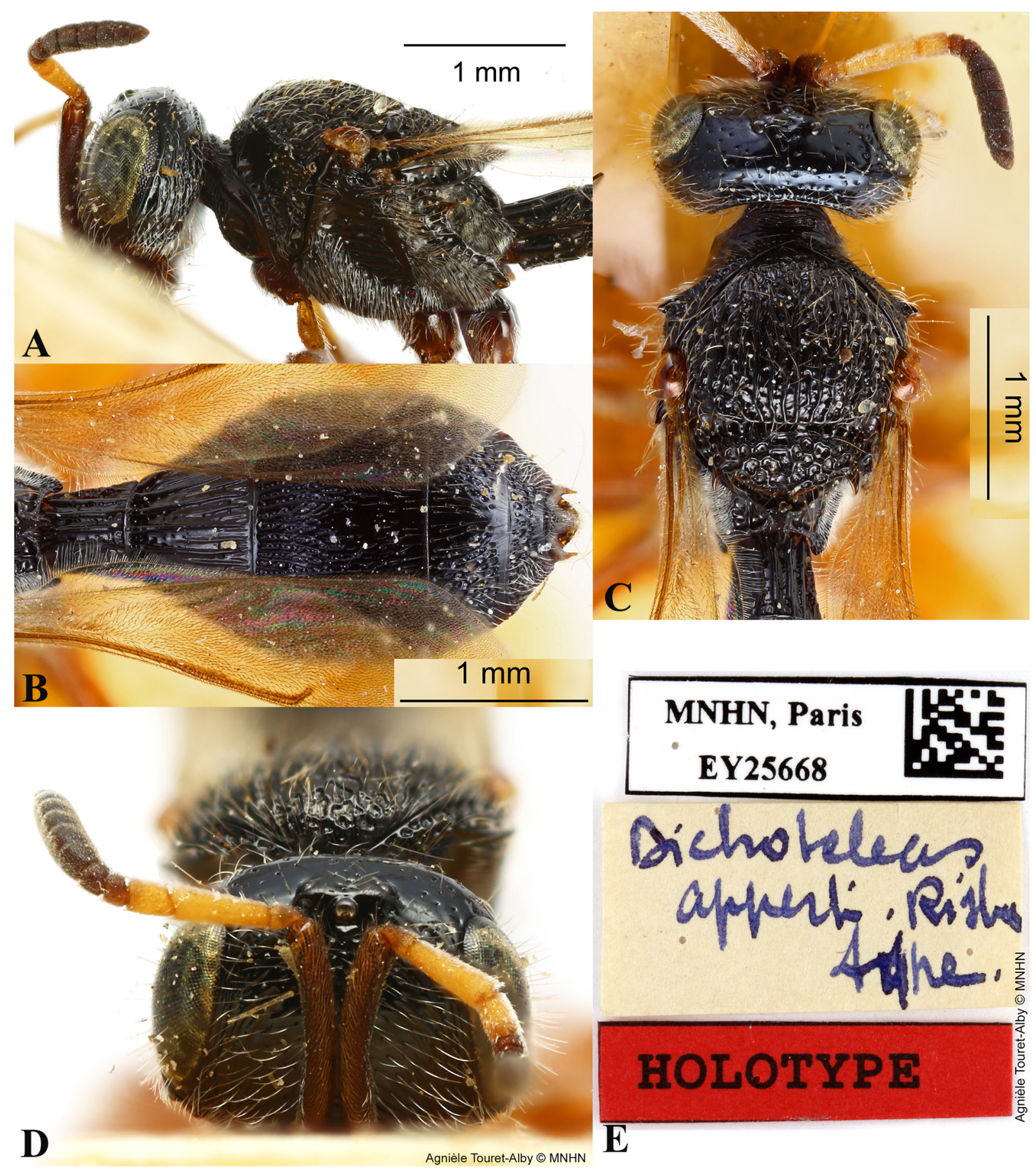

Fig. 6. Odontoscelio apperti (Risbec, 1953). Holotype, $q$ (MNHN EY25668). A. Head and pleuron. B. Metasoma. C. Head and mesoscutum. D. Frons, vertex and antennae. E. Type label. Photos: Agnièle Touret-Alby ${ }^{\mathcal{O}}, \mathrm{MNHN}$. 
$15.6: 9.3,43.0: 11.6,19.5: 11.6,7.0: 11.6,8.1: 12.8,10.5: 16.3,11.6: 17.4,11.6: 16.3,10.5: 16.3$, $10.5: 15.1,15.1: 12.8$, respectively.

Mesosoma (Figs 5, 6A, C). Cervical pronotal area transversely carinate; mesoscutum (L:W = 98.7: 122.7) anteromedially areolate, remainder longitudinally carinate, space between carinae smooth with setigerous foveae; pronotal shoulders with a wide spine, visible when viewed dorsally in addition to a spine above tegula; pronotal cervical sulcus foveate; lateral pronotal area dorsally foveate and setose, anteriorly smooth and posteriorly with intricate sculpture; netrion with large foveae; dorsal mesopleuron with a rectangular, transversely carinate patch beneath tegula; mesopleural pit distinct; speculum transversely carinate; mesepimeral sulcus not foveate; femoral depression with several transverse carinae, some of which extend the entire width; anterior episternum and ventral mesopleuron densely setose, obscuring sculpture; metapleuron anteriorly foveate, densely setose, posteriorly with large depressions; posterior margin of metapleuron with a wide spine; scutoscutellar sulcus foveate; mesoscutellum ( $\mathrm{L}: \mathrm{W}=36.0$ :93.3) areolate with setigerous punctae; median keel absent; metascutellum smooth, posteromedially with a wide spine, metanotal trough foveate; lateral propodeal area densely setose laterally, remainder longitudinally carinate, space between carinae smooth; anterolateral margin of lateral propodeal area with a spine and posterolateral margin of lateral propodeal area extending as a blunt spine. Fore wing $(\mathrm{L}: \mathrm{W}=329.5: 95.5)$ and hind wing $(\mathrm{L}: \mathrm{W}=279.5: 61.4)$ weakly infuscate.

Metasoma (Figs 5, 6B). L:W = 286.0:146.0; T1 longitudinally costate, space between costae predominantly smooth; T2 entirely longitudinally costate with shorter costae in between them on posterior half, except for a smooth patch laterally with setigerous punctae; T3 longitudinally costate on anterior half with foveae between costae, smooth on posterior half, laterally smooth with sparse setigerous punctae; T4 medially smooth with setigerous punctae, posteriorly smooth, remainder areolate, setose; T5 areolate, setose except for smooth posterior margin; T6 anteromedially punctate, with two densely setose, large lateral teeth and a median lobe; T1 and T2 with sparse lateral setae, T3-T5 with dense setae posterolaterally; length and width of tergites T1-T6 in ratio of $46.0: 42.0,68.0: 56.0,92.0: 136.0$, $42.0: 134.0,20.0: 88.0,20.0: 42.0$, respectively.

\section{Male}

Unknown.

Odontoscelio brevicephalus (Risbec, 1956)

Figs 7-8

Macrogryon brevicephala Risbec, 1956: 371, fig. 3 (holotype, ô, MNHN).

Odontoscelio brevicephalus - Masner 1976: 72 (transferred from Macrogryon).

\section{Material examined}

Syntypes (images only)

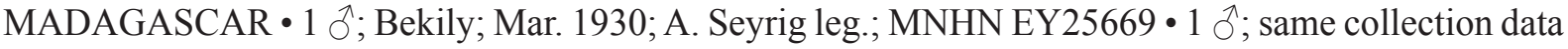
as for preceding but Feb. 1940; MNHN EY25670.

\section{Redescription}

Male

Body LeNGTH. $5.05(4.4-5.7) \mathrm{mm}$.

Colour (Figs 7, 8A-E). Body predominantly black, tegula brown, legs and mandibles reddish brown; radicle brown, remaining antennomeres dark brown. 
Head (Figs 7, 8A, C-E). $1.38 \times$ as wide as high, $2.1 \times$ as high as long; IOS $0.64 \times$ head width, $1.35 \times$ eye length; OOL $>$ POL $>$ LOL in ratio of 33.0:24.0:13.0; OOL $3.4 \times$ OD; eye (L:W $=65.1: 40.2)$ setose; frons with oblique carinae, some dorsal carinae converge medially into a smooth area; space between carinae smooth with setigerous punctae; frons above interantennal process with semicircular carinae; vertex with uneven sized depressions; ocelli not raised above surface of vertex; sparse transverse carinae present between posterior ocellus and orbit; interocellar area with setigerous foveae; occiput with transverse carinae, space between carinae with setigerous punctae; occipital carina not foveate; upper gena with longitudinal carinae, remainder smooth; entire gena with setigerous punctae.

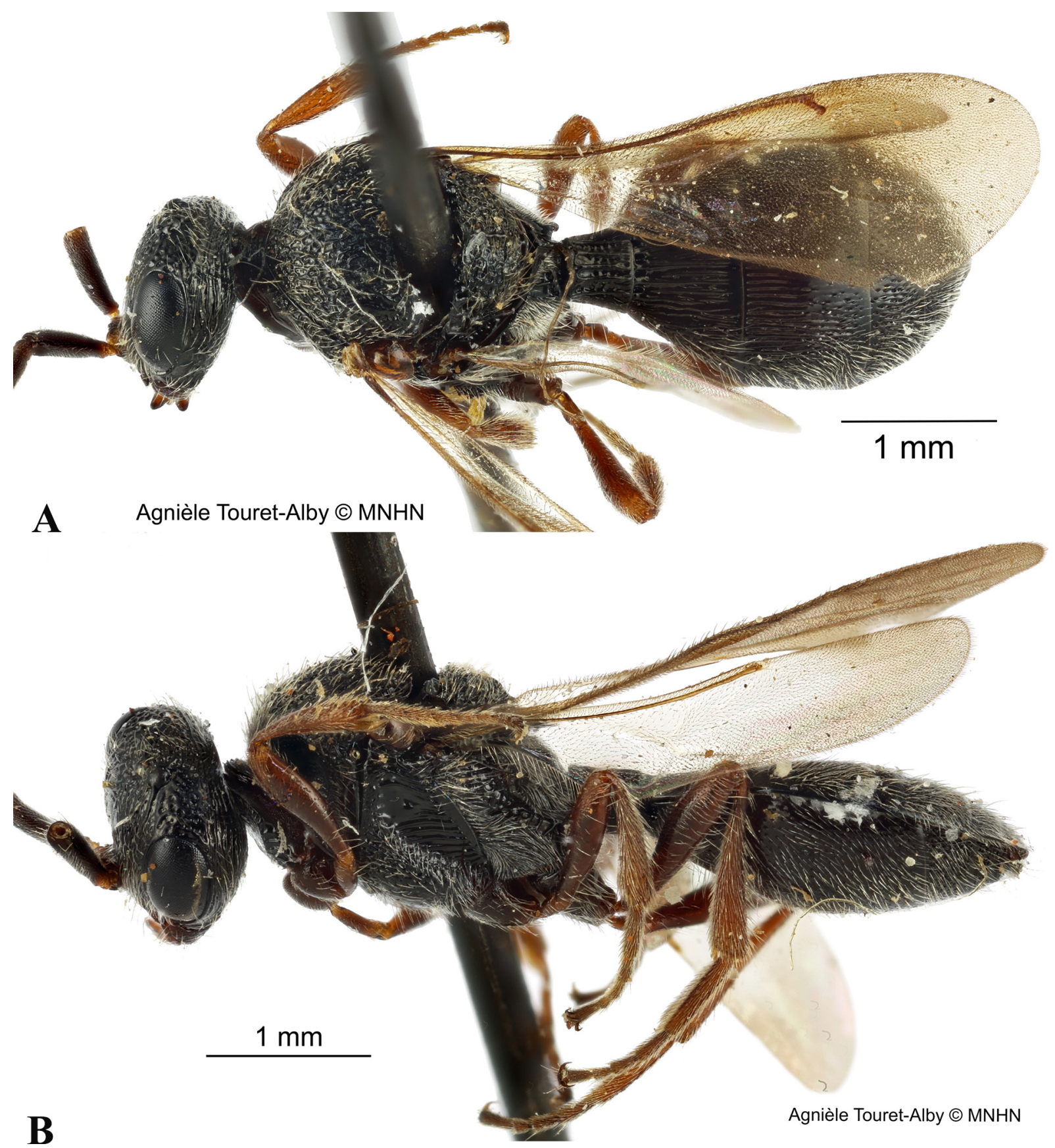

Fig. 7. Odontoscelio brevicephalus (Risbec, 1956). Syntype, $\widehat{\partial}$ (MNHN EY25669). A. Habitus (dorsal view). B. Habitus, (lateral view). Photos: Agnièle Touret-Alby ${ }^{\mathcal{O}}$, MNHN. 


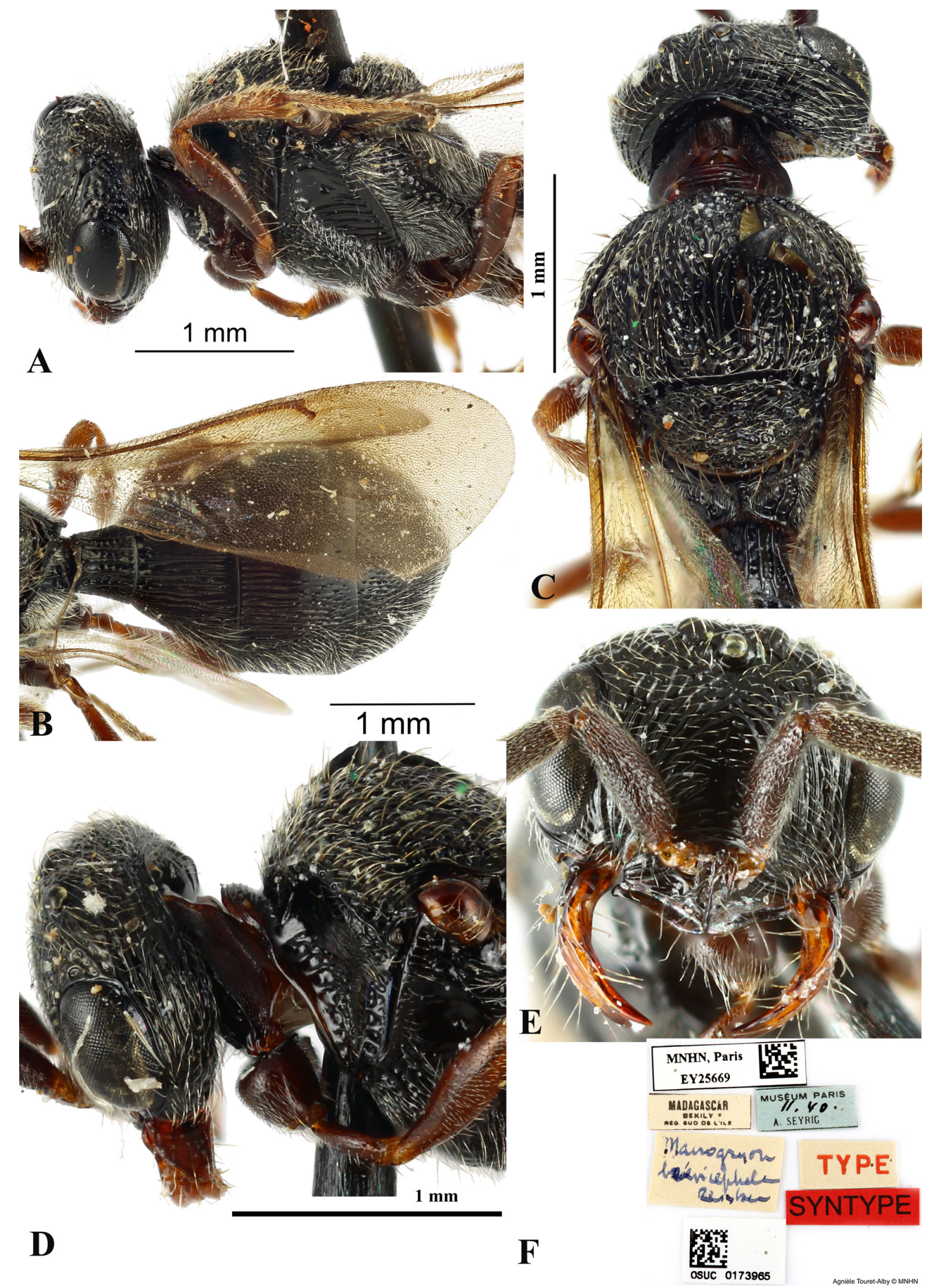

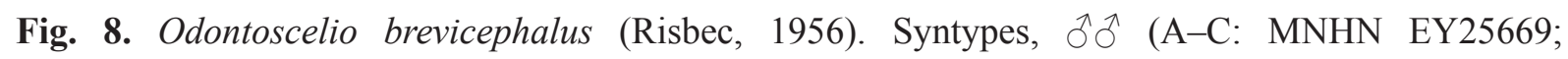
D-E: MNHN EY25670). A. Head and pleuron. B. Metasoma. C. Head and mesonotum. D. Head and lateral pronotal area. E. Frons. F. Type label. Photos: Agnièle Touret-Alby ${ }^{\mathcal{O}}, \mathrm{MNHN}$. 
Mesosoma (Figs 7, 8A, C-D). Cervical pronotal area transversely carinate; mesoscutum (L:W = $94.0: 130.4)$ anteriorly areolate, with long setae, remainder longitudinally carinate, space between them setigerous foveate; pronotal cervical sulcus foveate, remainder of lateral pronotal area smooth except for a narrow patch of rugose sculpture above pronotal cervical sulcus; netrion foveate; dorsal mesopleuron without a rectangular, transversely carinate patch beneath tegula; mesopleural pit distinct; speculum transversely carinate, space between carinae smooth; mesepimeral sulcus foveate anteriorly; several transverse carinae present on femoral depression ventral to mesopleural pit, some of which extend $2 / 3$ width of mesopleuron; episternum foveate and ventral mesopleuron setigerous punctate, setae sparse; metapleuron anteriorly foveate, densely setose, posteriorly with large depressions without setae; scutoscutellar sulcus foveate laterally; mesoscutellum ( $\mathrm{L}: \mathrm{W}=47.7: 93.2)$ areolate with several setigerous punctae; median keel present; metascutellum predominantly smooth, posteromedially with a triangular spine, metanotal trough foveate; lateral propodeal area laterally densely setose, remainder smooth with small foveae between longitudinal carinae; lateral propodeal area anterolaterally with a short spine; posterolateral margin of lateral propodeal area extending as a blunt in-curved spine. Fore wing $(\mathrm{L}: \mathrm{W}=347.1: 120.7)$ and hind wing $(\mathrm{L}: \mathrm{W}=286.7: 60.3)$ weakly infuscate.

Metasoma (Figs 7, 8B). L:W = 256.6:160.5; T1 longitudinally costate, space between costae foveate; T2 with basal foveae, remainder longitudinally costate, space between costae smooth with sparse punctae; T3 medially longitudinally costate on anterior half, posterior half smooth with setigerous punctae; remaining tergites smooth with setigerous punctae; T1 and T2 laterally sparsely setose; T3-T6 laterally with dense short setae; length and width of tergites T1-T7 in ratio of $42.1: 42.1,69.7 .3: 60.5$, $80.3: 155.3,33.5: 155.3,14.8: 101.9,7.5: 55.6,5.6: 24.1$, respectively.

\section{Female}

Unknown.

Odontoscelio caelebs (Nixon, 1936)

Figs 9-10

Macrogryon caelebs Nixon, 1936: 189, fig. 18 (holotype, , NHMUK).

Macrogryon caelebs - Masner 1965: 99 (type information).

Odontoscelio caelebs - Masner 1976: 72 (generic transfer from Macrogryon).

\section{Material examined}

Holotype (images only)

MALAWI • ; Mangochi [labelled: Fort Johnston, Nyasaland]; Feb. 1922; Dr W.A. Lamborn leg.; taken crawling on sand; NHMUK 013379412.

\section{Redescription}

Female

Body LengTh. $7.0 \mathrm{~mm}$.

Colour (Figs 9, 10A-E). Body black, tegula, interantennal process, mandibles and legs brownish black; radicle brown, A1 black, A2-A4 brownish black.

HeAD (Figs 9, 10A, D-E). Head $1.32 \times$ as wide as high, $1.45 \times$ as high as long; IOS $0.60 \times$ head width, $1.3 \times$ eye length; $\mathrm{OOL}>\mathrm{POL}>\mathrm{LOL}$ in ratio of $35.4: 18.9: 10.4$; OOL $3.9 \times \mathrm{OD}$; eye $(\mathrm{L}: \mathrm{W}=75.9: 48.0)$ setose; dorsal frons areolate with setigerous punctae, with semicircular carinae above interantennal process, smooth medially, remainder with oblique carinae radiating towards centre interspersed with 
setigerous punctae; interantennal process foveate, setose; vertex areolate with setigerous punctae, interocellar area predominantly smooth; ocelli not raised above surface of vertex; occiput carinate; occipital carina foveate; gena longitudinally carinate, interspersed with setigerous punctae; length and width of antennomeres A1-A4 in ratio of $98.0: 14.7,14.7: 9.8,46.1: 14.7,16.7: 14.7$, respectively.

Mesosoma (Figs 9, 10A, C). Cervical pronotal area transversely carinate; mesoscutum (L:W = $114.0: 132.8)$ anteriorly areolate interspersed with setigerous punctae, remainder with longitudinal carinae, space between carinae with setigerous foveae; pronotal shoulders with a wide spine, visible when viewed dorsally; lateral pronotal area dorsally areolate, setose, posteroventrally weakly transversely striate, remainder smooth; pronotal cervical sulcus foveate; netrion foveate; dorsal mesopleuron without a rectangular, transversely carinate patch beneath tegula; mesopleural pit distinct; speculum transversely carinate; mesepimeral sulcus not foveate; femoral depression transversely carinate; anterior episternum foveate, setose; postacetabular sulcus transversely carinate; ventral mesopleuron foveate, densely setose; metapleuron anteriorly densely setose, posteriorly with large depressions; scutoscutellar sulcus foveate laterally; mesoscutellum $(\mathrm{L}: \mathrm{W}=51.5: 117.1)$ areolate, median keel present; metascutellum foveate, posteromedially with a triangular spine, metanotal trough foveate; lateral propodeal area laterally densely setose, remainder longitudinally carinate, space between carinae smooth; posterolateral margin of lateral

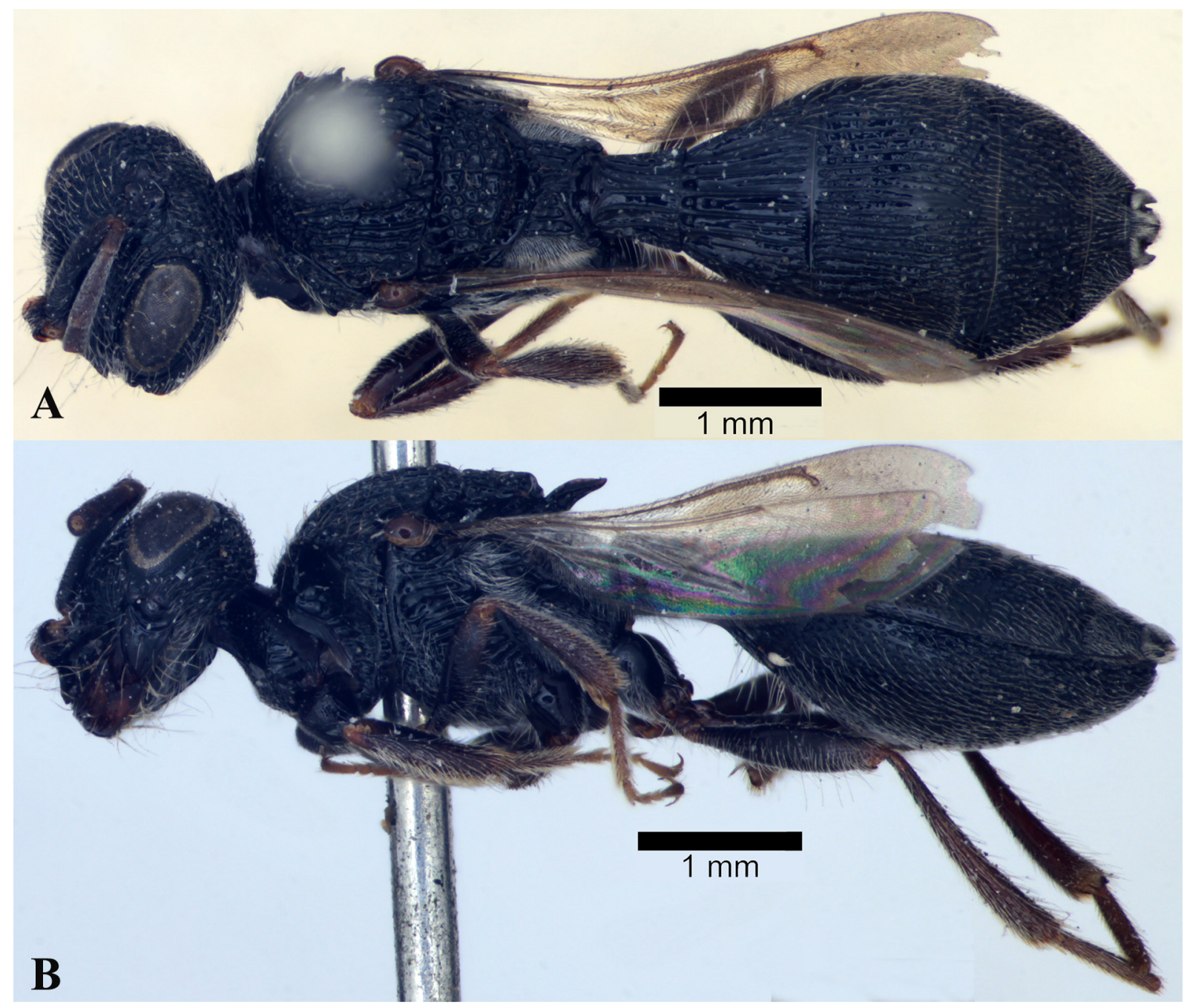

Fig. 9. Odontoscelio caelebs (Nixon, 1936). Holotype, $q$ (NHMUK 013379412). A. Habitus (dorsal view). B. Habitus (lateral view). Photos: D.G. Notton ${ }^{\odot}$, NHMUK. 
propodeal area extending posteriorly as a blunt, in-curved spine. Fore wing $(\mathrm{L}: \mathrm{W}=304.3: 102.1)$ and hind wing $(\mathrm{L}: \mathrm{W}=271.7: 71.7)$ weakly infuscate.

Metasoma (Figs 9, 10B). ( $\mathrm{L}: \mathrm{W}=356.7: 188.7)$; T1 predominantly longitudinally costate, space between costae smooth; T2 with basal foveae, remainder longitudinally costate, space between costae

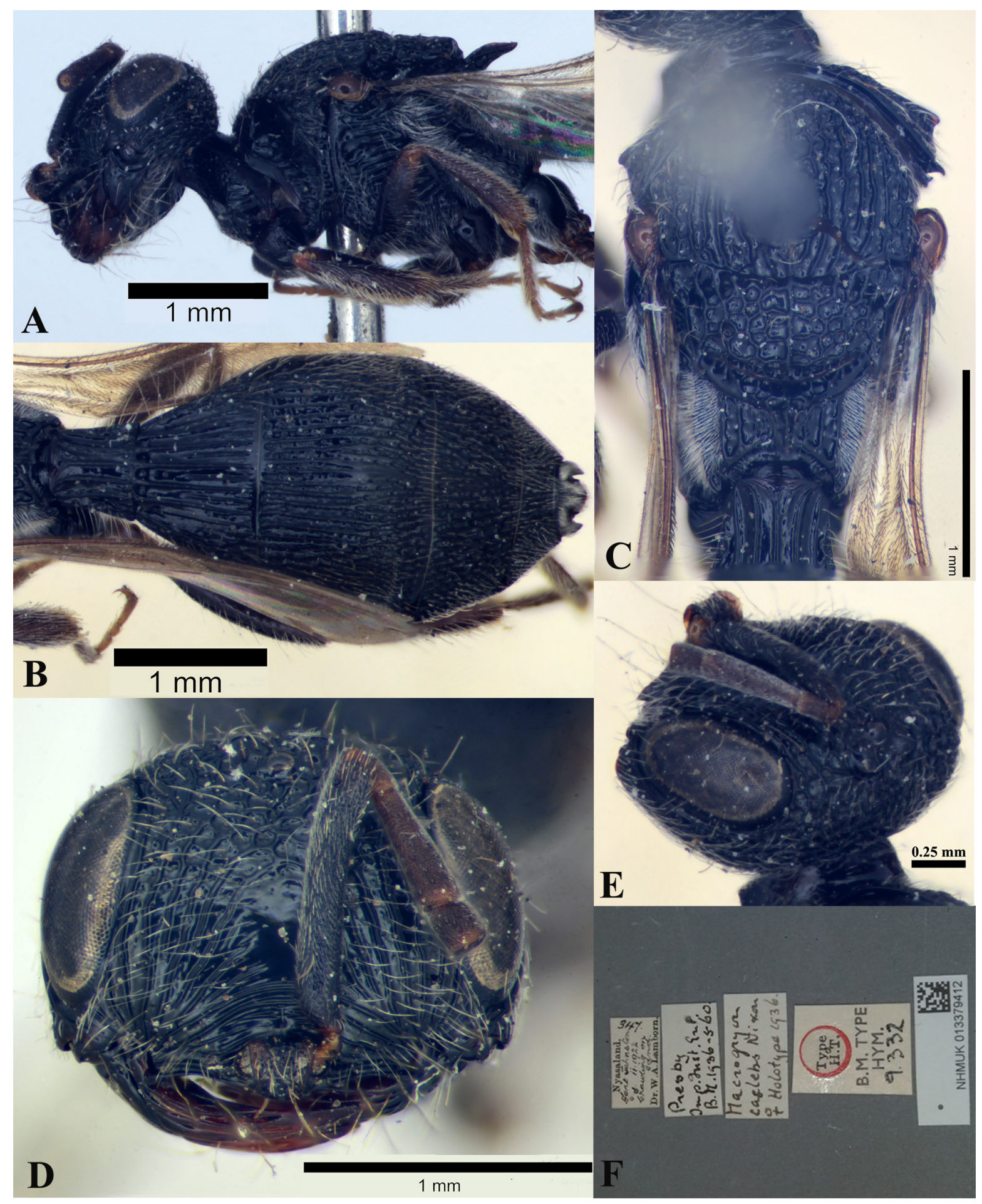

Fig. 10. Odontoscelio caelebs (Nixon, 1936). Holotype, $q$ (NHMUK 013379412). A. Head and pleuron. B. Metasoma. C. Mesonotum. D. Frons. E. Head. F. Type label. Photos: D.G. Notton ${ }^{\odot}$, NHMUK. 
with carinae posteriorly; T3 longitudinally costate, space between costae foveate, with short setae; T3 with a row of setigerous punctae on posterior margin, followed by a smooth patch; T4 medially smooth with sparse setigerous punctae, remainder with large depressions with setae; T5 setigerous punctate; T6 with two large teeth laterally and a median lobe, both densely setose; T1 and T2 sparsely setose laterally, T3 laterally punctate with a mix of dense short and long setae, T4 with dense setae laterally; length and width of tergites T1-T6 in ratio of $54.2: 52.3,81.3: 63.6,112.1: 168.2,57.9: 172.0$, $20.6: 112.1,20.6: 56.1$, respectively.

Odontoscelio echion (Nixon, 1936)

Figs $11-12$

Macrogryon echion Nixon, 1936: 190 (holotype, đે, NHMUK).

Macrogryon echion - Masner 1965: 99 (type information).

Odontoscelio echion - Masner 1976: 72 (transfer from Macrogryon).

\section{Material examined}

Syntype (images only)

SOUTH AFRICA 1 O ; Eastern Cape Province, Wild Coast, Pondoland, Port St. John; Dec. 1923; R.E. Turner leg.; NHMUK 013379413 [5 other syntype ô $\widehat{\partial}$ with the same collection data not examined].

\section{Redescription}

Male

Body LENGTH. $5.4 \mathrm{~mm}$.

Colour (Figs 11, 12A-D, F). Body black; tegula and mandibles brown; interantennal process dark brown; radicle brown, A2 a shade darker than radicle, remaining antennomeres dark brown; legs in shades of brown; anterior T1 reddish brown.

HeAD (Figs 11, 12A, C-D, F). Head $1.15 \times$ as wide as high, $1.65 \times$ as high as long; IOS $0.66 \times$ head width, $1.84 \times$ eye length; $\mathrm{OOL}>\mathrm{POL}>\mathrm{LOL}$ in ratio of $30.8: 16.8: 8.0$; OOL $3.3 \times \mathrm{OD}$; eye $(\mathrm{L}: \mathrm{W}=44.5: 34.2)$ setose; frons with oblique carinae extending towards centre; carinae in upper and lower frons do not converge medially; carinae present in medial frons, converge medially and are further connected with each other by a longitudinal carina; space between carinae smooth with long brown setae; interantennal process weakly foveate; vertex, interocellar area and occiput with setigerous punctae; occipital carina weakly foveate; ocelli not raised above surface of vertex; gena longitudinally carinate with setigerous punctae; length and width of antennomeres A1-A11 in ratio of $56.3: 14.6,8.3: 8.3,52.1: 12.5,37.5: 13.5$, $33.3: 12.5,41.7: 14.6,43.8: 14.6,47.9: 13.5,47.9: 13.5,50.0: 13.5,45.8: 13.5$, respectively.

Mesosoma (Figs 11, 12A, C). Mesoscutum (L:W= 68.7:114.2) with longitudinal carinae, space between carinae smooth, with setigerous punctae and sparse weak foveae; pronotal shoulders without a spine laterally; lateral pronotal area dorsally foveate and setose, medially smooth; pronotal cervical sulcus weakly foveate, with additional sparse foveae anteriorly; netrion not distinct; dorsal mesopleuron with a triangular, transversely carinate patch beneath tegula; mesopleural pit distinct; speculum transversely carinate; mesepimeral sulcus foveate, foveae elongate; femoral depression with three transverse carinae beneath medial smooth area; anterior episternum and ventral mesopleuron with setigerous foveae, interspersed with transverse carinae; metapleuron anteriorly with setigerous foveae, posterodorsally foveate, posteroventrally smooth with short transverse carinae; scutoscutellar sulcus laterally with large 
foveae; mesoscutellum $(\mathrm{L}: \mathrm{W}=50: 100)$ areolate; median keel not distinct; metascutellum foveate and posteromedially with a triangular spine, metanotal trough foveate; lateral propodeal area laterally densely setose, remainder with longitudinal rows of foveae; propodeum anterolaterally with a spine; posterolateral margin of lateral propodeal area extending posteriorly as a blunt, straight spine. Fore wing $(\mathrm{L}: \mathrm{W}=352.9: 97.0)$ and hind wing $(\mathrm{L}: \mathrm{W}=300.0: 58.8)$ weakly infuscate.

Metasoma (Figs 11, 12B). L:W=264.7:122.1; T1 anteromedially smooth with sparse foveae, remainder longitudinally costate, space between costae foveate; T2 with basal foveae, remainder longitudinally costate, space between costae with shorter costae posteriorly; T3 predominantly longitudinally costate, space between costae foveate; T3 laterally with setigerous punctae, posteriorly with a row of setigerous punctae followed by a smooth patch; remaining tergites setigerous punctate, punctae dense laterally on T4-T6; T1 and T2 with sparse long setae laterally, T3-T6 densely setose laterally; length and width of tergites T1-T7 in ratio of 45.6:36.8, 64.0:63.2, 77.9:117.6, 36.8:120.6, 20.6:89.7, 11.8:58.8, $7.4: 36.8$, respectively.
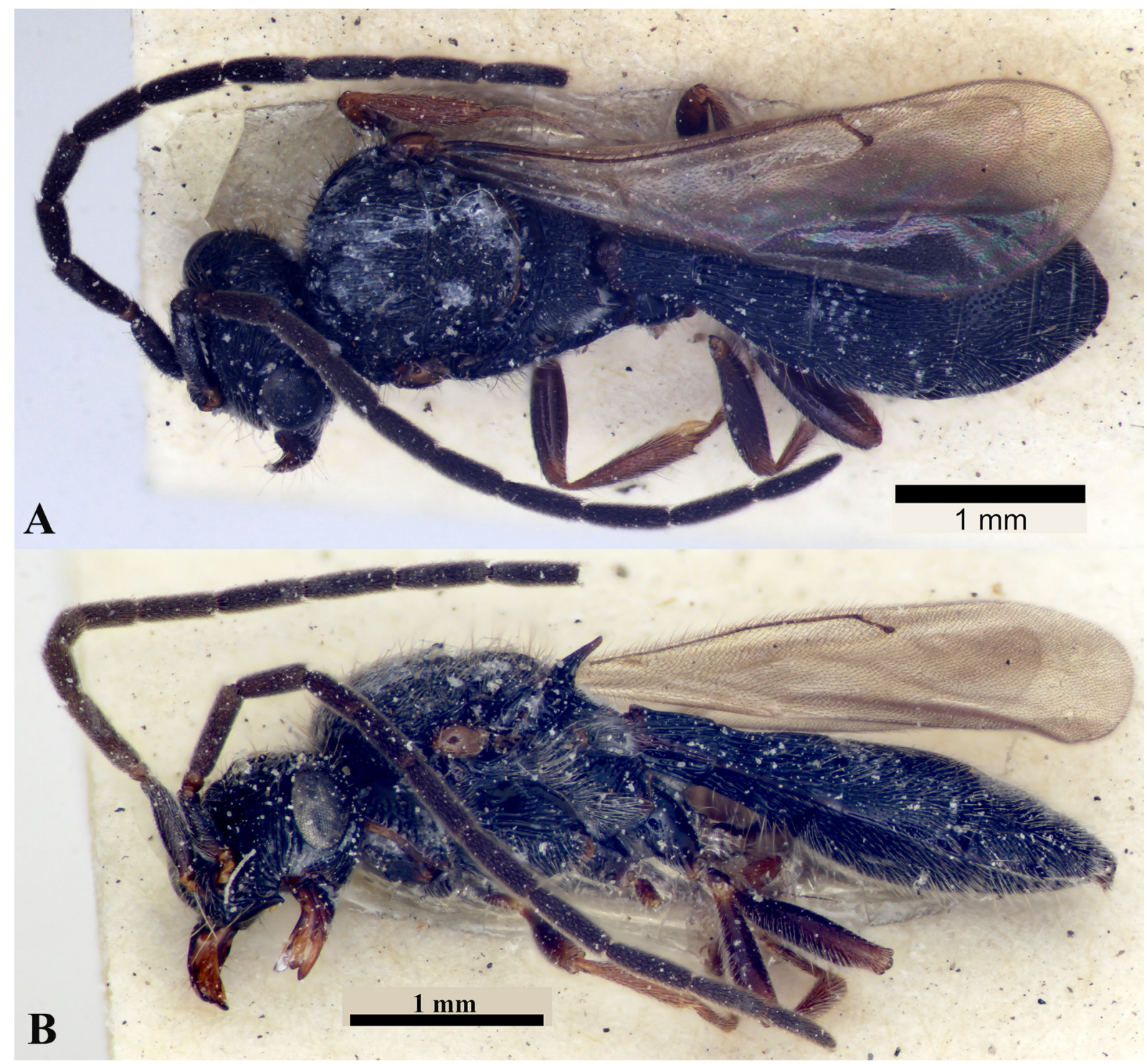

Fig. 11. Odontoscelio echion (Nixon, 1936). Syntype, ô (NHMUK 013379413). A. Habitus (dorsal view). B. Habitus (lateral view). Photos: D.G. Notton ${ }^{\odot}$, NHMUK. 


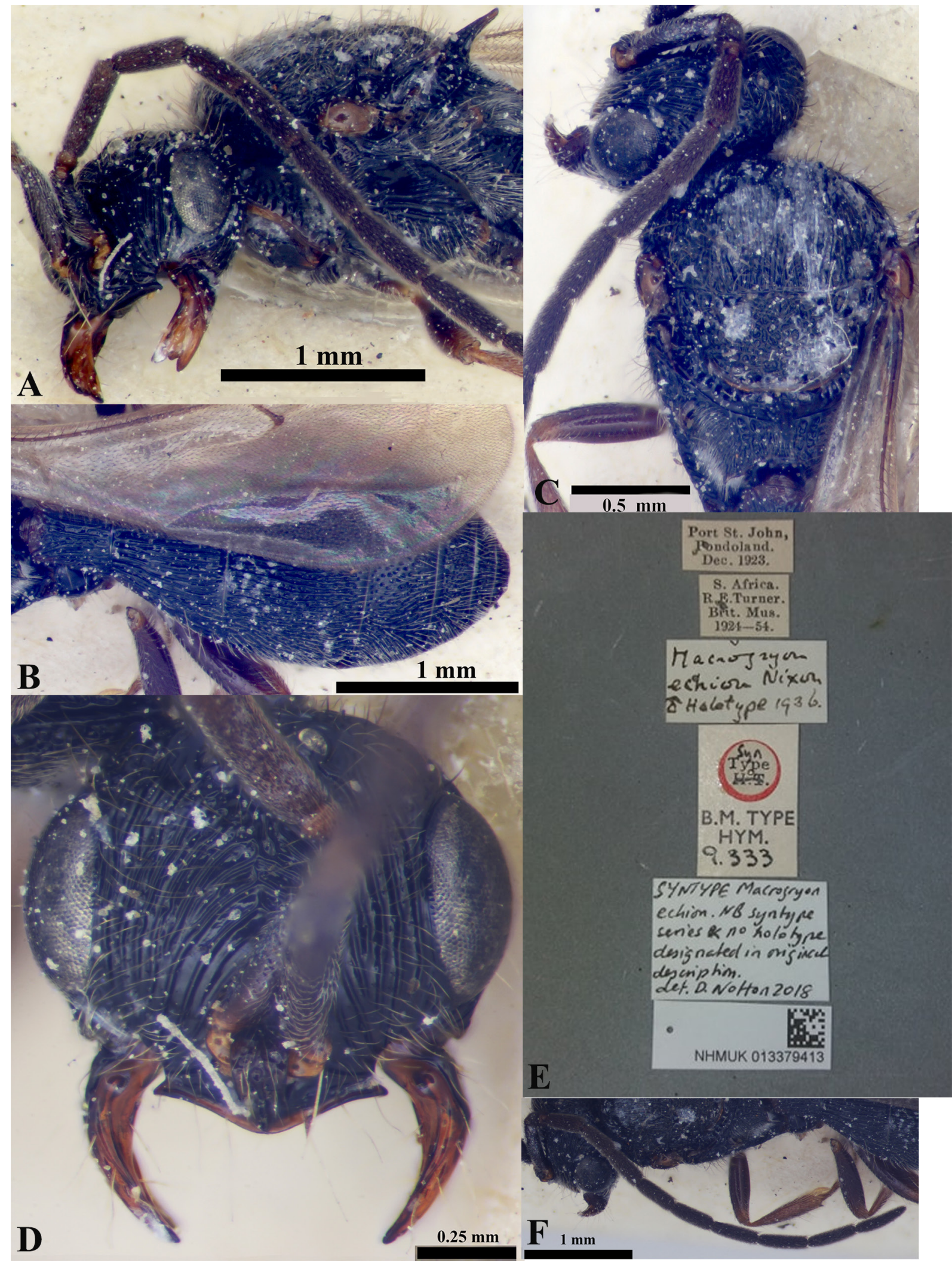

Fig. 12. Odontoscelio echion (Nixon, 1936). Syntype, ô (NHMUK 013379413). A. Head and pleuron. B. Metasoma. C. Head and mesonotum. D. Frons. E. Type label. F. Antenna. Photos: D.G. Notton ${ }^{\odot}$, NHMUK. 
Odontoscelio laticephalus (Risbec, 1950)

Figs 13-14

Hoplogryon laticephalus Risbec, 1950: 581, fig. 59 (holotype, §̂, MNHN).

Odontoscelio laticephalus - Masner 1976: 72 (transfer from Hoplogryon).

\section{Material examined}

Syntypes (images only)

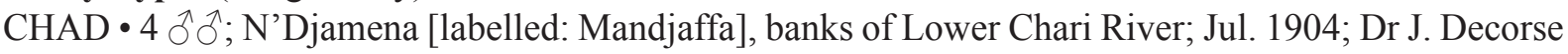
leg.; Chari-Chad mission; MNHN EY25672 to EY25675.

\section{Redescription}

\section{Male}

BODY LENGTH. $3.6 \mathrm{~mm}$.

Colour (Figs 13, 14A-D). Body predominantly black, tegula brown, interantennal process yellowish brown; radicle and basal A1 yellowish brown, apical $2 / 3$ of A1 brown, remaining antennomeres dark brown; coxae brown, remainder of leg yellowish brown; anterior T1 brown.

HeAD (Figs 13, 14A, C-D). Head $1.19 \times$ as wide as high, $2.0 \times$ as high as long; IOS $0.68 \times$ head width, $1.45 \times$ eye length; $\mathrm{OOL}>\mathrm{POL}>\mathrm{LOL}$ in ratio of $17.4: 16.8: 9.00 ; \mathrm{OOL} 2.8 \times \mathrm{OD}$; eye $(\mathrm{L}: \mathrm{W}=39.6: 23.6)$ setose; frons medially from interantennal process to anterior ocellus smooth without setae, remainder with oblique carinae directed inwards; space between carinae smooth with long setigerous punctae; a short longitudinal carina present beneath anterior ocellus; all three ocelli connected by carinae; ocelli raised above surface of vertex; vertex and interocellar area predominantly smooth; occiput and gena longitudinally carinate, space between carinae with setigerous punctae; occipital carina weakly foveate; length and width of antennomeres A1-A11 in ratio of $36.7: 7.8,6.7: 6.1,33.3: 7.8,26.7: 7.8,20.0: 7.2$, $23.3: 6.7,26.7: 7.2,27.8: 7.8,27.8: 5.6,26.7: 5.6,26.7: 5.6$, respectively; setae on antennomeres sparse.

Mesosoma (Figs 13A-C, 14A, C). Cervical pronotal area transversely carinate; mesoscutum (L:W = $48.2: 81.4$ ) anteriorly areolate, remainder longitudinally carinate and space between carinae unevenly smooth with setigerous foveae; pronotal shoulders without a lateral wide spine; lateral pronotal area predominantly smooth, except for a dense setose patch posteriorly; pronotal suprahumeral sulcus and pronotal cervical sulcus foveate; netrion not distinct; dorsal mesopleuron with a rectangular, weakly transversely carinate patch beneath tegula; mesopleural pit distinct; speculum transversely carinate; mesepimeral sulcus not foveate; femoral depression medially smooth, with several short transverse carinae posteroventrally; episternal foveae present; anterior episternum and ventral mesopleuron entirely with setigerous foveae; metapleuron anteroventrally densely setose, metapleural sulcus foveate, remainder with intricate sculpture; scutoscutellar sulcus foveate laterally; mesoscutellum ( $\mathrm{L}: \mathrm{W}=27.3: 59.2)$ predominantly areolate except for a smooth patch anteromedially; median keel distinct posteriorly; metascutellum foveate with posteromedially triangular spine, metanotal trough foveate; lateral propodeal area setose, with indistinct foveae; propodeum anterolaterally with a large blunt spine; posterolateral margin of lateral propodeal area extending posteriorly as a blunt spine. Fore wing ( $\mathrm{L}: \mathrm{W}=212.4: 72.5)$ and hind wing $(\mathrm{L}: \mathrm{W}=180.8: 31.5)$ weakly infuscate.

Metasoma (Figs 13A-C, 14B). L: W = 140.2: 86.2; T1 longitudinally costate, space between costae weakly foveate; T2 with basal foveae, remainder longitudinally costate, space between them with short costae posteriorly; T3 medially densely foveate, remainder longitudinally carinate (with foveae between carinae) except for a smooth posterior margin; T4 and T5 with setigerous punctae, with smooth 

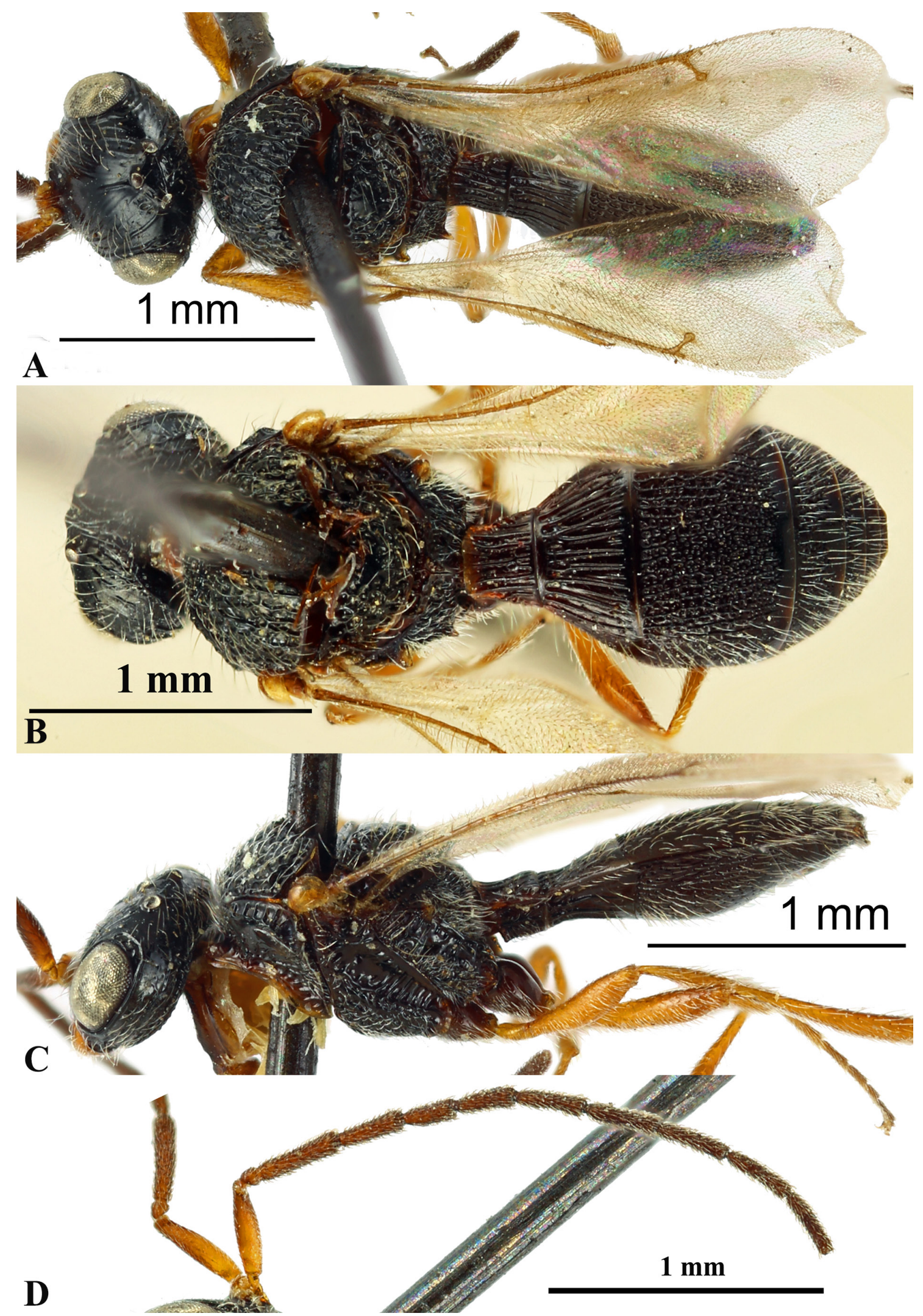

Fig. 13. Odontoscelio laticephalus (Risbec, 1950). Syntypes, $\widehat{\jmath} \widehat{\jmath}$ (A, C: MNHN EY25673; B: MNHN EY25672; D: MNHN EY25674). A. Habitus (dorsal view). B. Habitus (dorsal view). C. Habitus (lateral view). D. Antenna. Photos: Agnièle Touret-Alby ${ }^{\odot}$, MNHN. 
posterior margins; T1 and T2 with sparse long setae laterally, T3-T6 with dense setae laterally; T6 and T7 smooth, with sparse setae; length and width of tergites T1-T7 in ratio of $26.4: 253,34.5: 35.6$, $57.5: 82.8,18.4: 80.5,6.9: 57.5,5.0: 36.8,2.3: 18.4$, respectively.

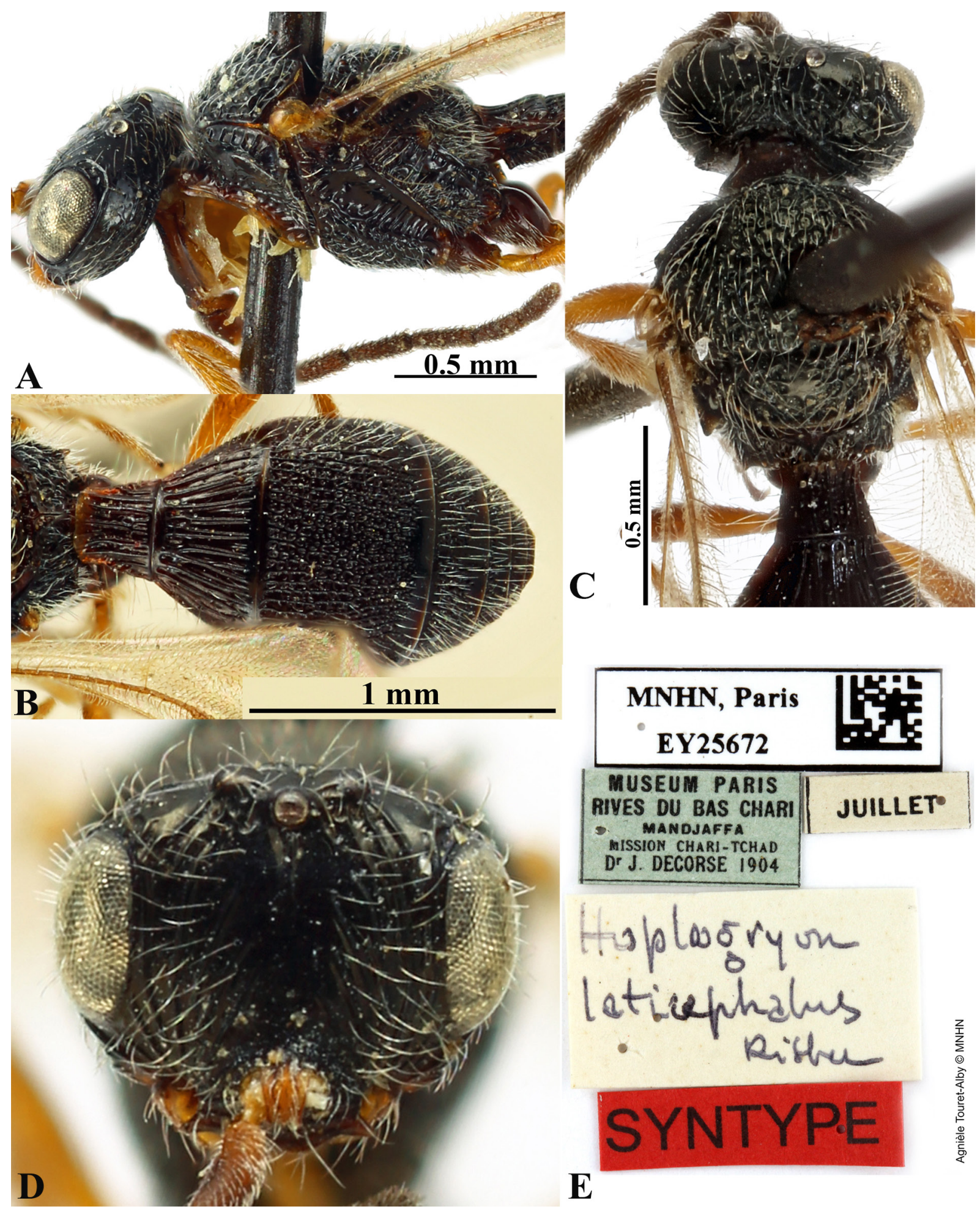

Fig. 14. Odontoscelio laticephalus (Risbec, 1950). Syntypes, ð̊̊ (A: MNHN EY25673; B: MNHN EY25672; C-D: MNHN EY25675). A. Head and pleuron. B. Metasoma. C. Head and mesonotum. D. Frons. E. Type label. Photos: Agnièle Touret-Alby ${ }^{\odot}$, MNHN. 
Odontoscelio pluto (Nixon, 1936)

Figs 15-16

Macrogryon pluto Nixon, 1936: 186, fig. 17 (holotype, ふ̊, NHMUK).

Macrogryon pluto - Masner 1965: 99 (type information).

Odontoscelio pluto - Masner 1976: 72 (transfer from Macrogryon).

\section{Material examined}

Syntype (images only)

SOUTH AFRICA • 1 §’; East Cape Province, Katberg; alt. 4000 ft; Dec. 1932; R.E. Turner leg.; NHMUK 013379414 [24 other syntype ô $\hat{\sigma}$ with the same collection data (collected Dec. 1932-Feb. 1933) not examined].

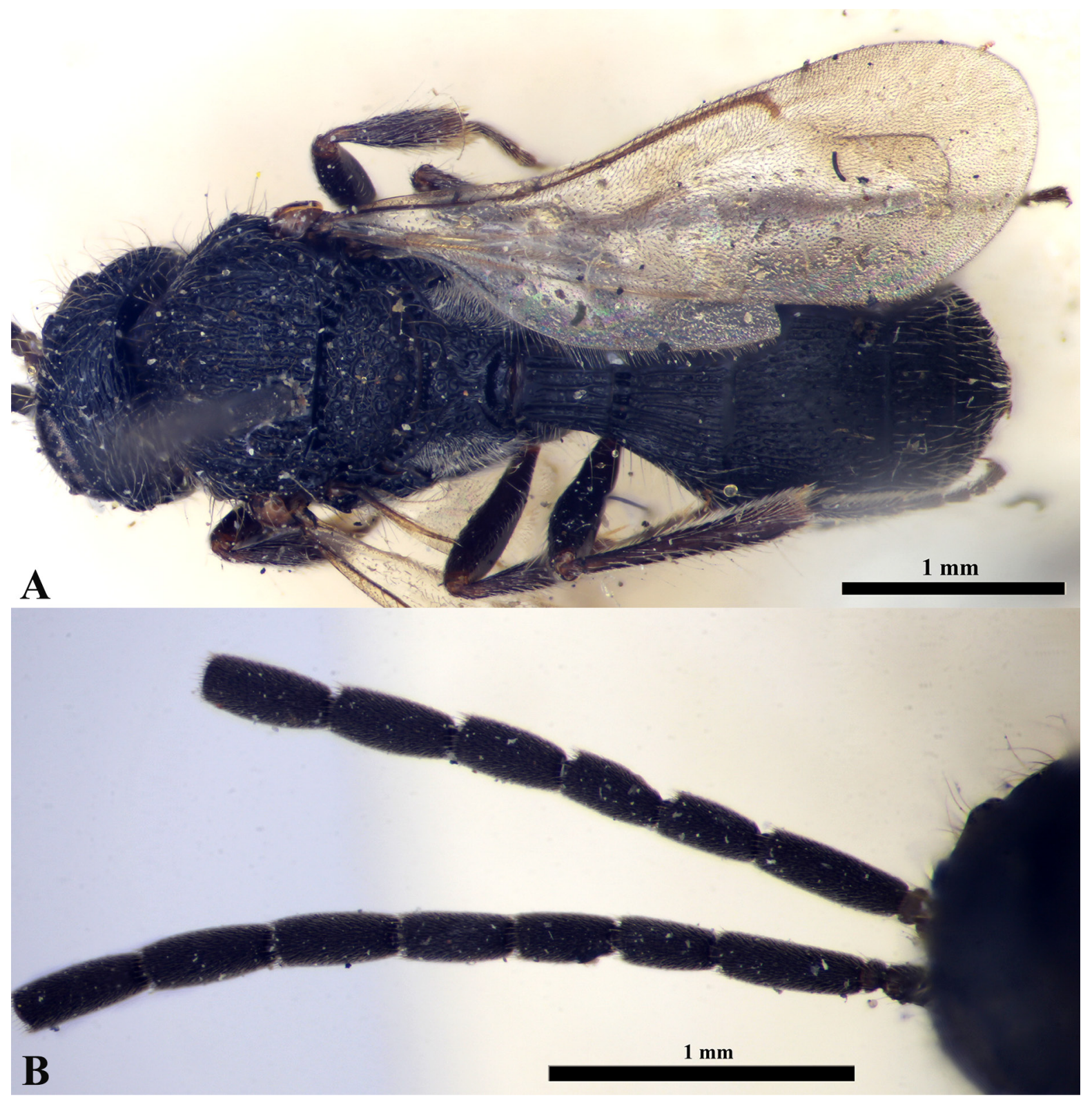

Fig. 15. Odontoscelio pluto (Nixon, 1936). Syntype, $\widehat{~}$ (NHMUK 013379414). A. Habitus, dorsal view. B. Antennae. Photos: D.G. Notton ${ }^{\circ}$, NHMUK. 
Other material (not examined)

SOUTH AFRICA • 1 đ̊; Transkei (Umtata); Feb.-Mar. 1933 • 1 đ̊; Cape Province, Queenstown; alt. 3500 ft; Feb.-Mar. 1933.

\section{Redescription}

Male

BODY LENGTH. $5.32 \mathrm{~mm}$.

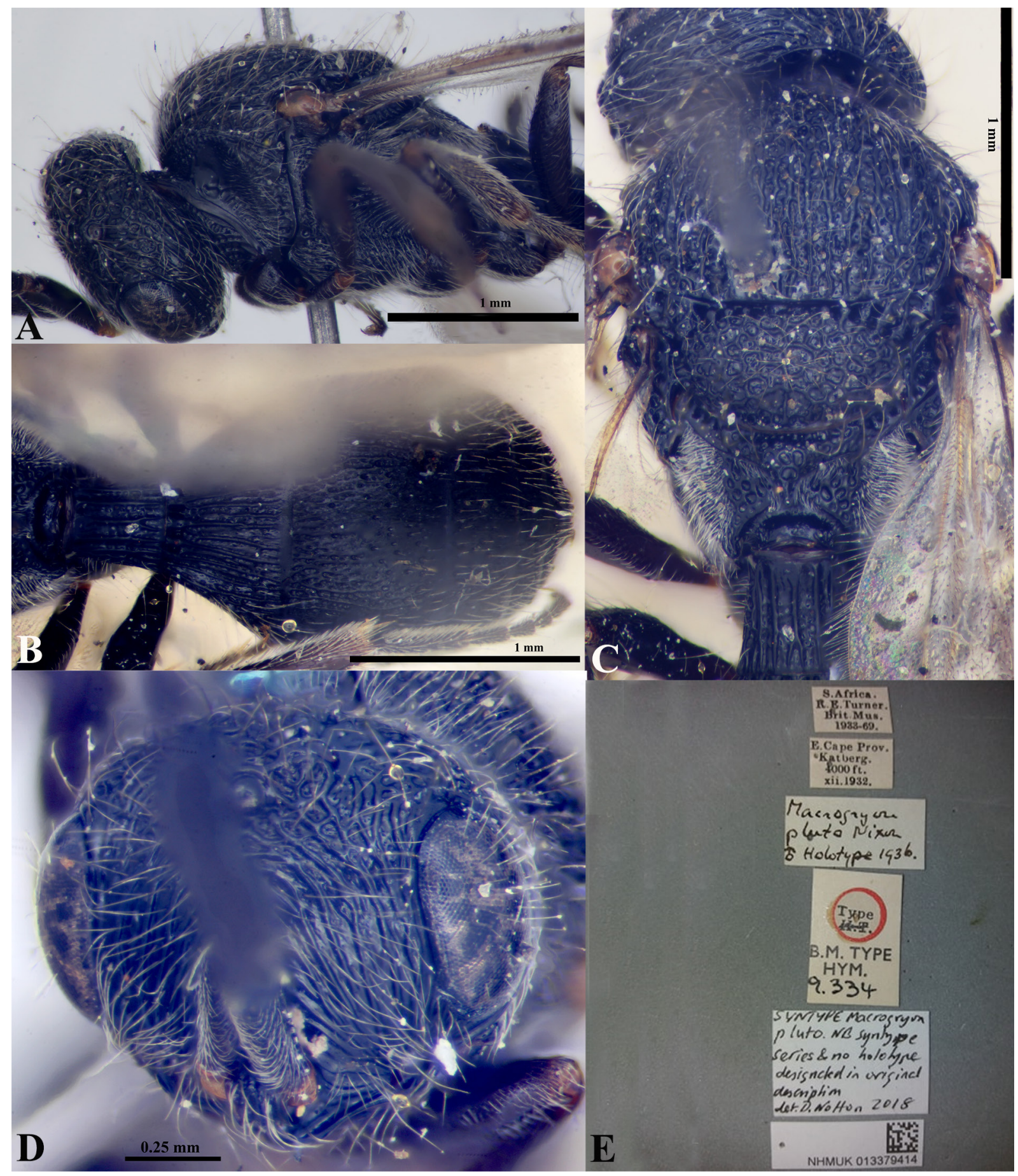

Fig. 16. Odontoscelio pluto (Nixon, 1936). Syntype, §̊ (NHMUK 013379414). A. Head and pleuron. B. Metasoma. C. Head and mesonotum. D. Frons. E. Type label. Photos: D.G. Notton ${ }^{\circ}$, NHMUK. 
Colour (Figs 15, 16A-D). Body predominantly black, tegula brown, interantennal process and legs brownish black; radicle brown, remaining antennomeres black.

HEAD (Figs 15, 16A, C, D). Head $1.15 \times$ as wide as high, $2.1 \times$ as high as long; IOS $0.65 \times$ head width, $1.5 \times$ eye length; $\mathrm{OOL}>\mathrm{POL}>\mathrm{LOL}$ in ratio of $31.0: 16.8: 11.4$; OOL $3.1 \times \mathrm{OD}$; eye $(\mathrm{L}: \mathrm{W}=57.2: 37.4)$ setose; upper frons areolate, remainder longitudinally carinate, space between carinae predominantly smooth with setigerous punctae; frons above interantennal process smooth; ocelli raised above surface of vertex; vertex and interocellar area with large areolae, setose; occiput carinate with setigerous foveae medially; occipital carina foveate; gena longitudinally carinate, interspersed with setigerous punctae; length and width of antennomeres A1-A9 in ratio of 59.7: 13.4, 9.0:9.7, 50.7: 16.4, 32.8: 14.9, $34.3: 16.4,37.3: 16.4,41.8: 16.4,44.8: 14.9,44.8: 14.9$, respectively.

Mesosoma (Figs 15A, 16A, C). Cervical pronotal area transversely carinate; mesoscutum (L:W = 84.6 : 98.4) anteriorly areolate, remainder longitudinally carinate, space between carinae unevenly smooth with setigerous punctae; pronotal shoulders without a wide lateral spine; lateral pronotal area dorsally areolate, posteriorly with sparse transverse carinae adjoined by a patch of intricate sculpture interspersed with short setae, remainder smooth, devoid of setae; pronotal cervical sulcus weakly foveate; netrion foveate; dorsal mesopleuron with a rectangular, transversely carinate patch beneath tegula; speculum transversely carinate; femoral depression with several transverse carinae posteroventrally; anterior episternum and ventral mesopleuron entirely with setigerous foveae; metapleuron densely setose; scutoscutellar sulcus foveate laterally; mesoscutellum $(\mathrm{L}: \mathrm{W}=46.1: 84.6)$ areolate, each areola with several setigerous punctae, median keel present posteriorly; metascutellum foveate, posteromedially with a triangular spine which is foveate basally, metanotal trough foveate; lateral propodeal area laterally densely setose, remainder foveate; lateral propodeal area anterolaterally with a short spine; posterolateral margin of lateral propodeal area extending posteriorly as a blunt spine. Fore wing $(\mathrm{L}: \mathrm{W}=$ $345.7: 121.4)$ and hind wing $(\mathrm{L}: \mathrm{W}=229.9: 61.6)$ weakly infuscate.

Metasoma (Figs 15A, 16B). L:W = 217.6:128.3; T1 longitudinally costate, space between costae foveate; T2 with basal foveae, remainder longitudinally costate, space between costae smooth to weakly foveate; T3 medially smooth with sparse setigerous punctae, remainder longitudinally costate, space between costae foveate, with short setae; remaining tergites smooth with setigerous punctae; T1 and T2 laterally with setigerous punctae, T4-T6 laterally densely setose; length and width of tergites T1-T7 in ratio of $43.3: 54.8,55.7: 53.0,70.7: 119.4,29.2: 123.8,14.8: 95.5,5.3: 61.9,5.3: 31.0$, respectively.

\section{Odontoscelio striatifrons Kieffer, 1905}

Figs $17-18$

Odontoscelio striatifrons Kieffer, 1905: 14 (holotype, ð̊, MCSN).

Odontoscelio striatifrons - Kieffer 1926: 350 (description). — Bin 1974: 457 (type information).

\section{Material examined}

Holotype (images only)

GUINEA BISSAU • 1 ک̊; Bolama [labelled: Bolama, Portuguese Guinea]; Jun.-Dec.1899; L. Fea leg.; MCSN.

\section{Redescription}

Male

Body Length. $5.7 \mathrm{~mm}$.

Colour (Figs 17, 18A-E). Body black; tegula and mandibles brown; coxa black and remainder of leg brown; radicle brown, remaining antennomeres dark brown. 
HeAd (Figs 17, 18A, C-D). Head 1.19 $\times$ as wide as high, $1.9 \times$ as high as long; IOS $0.61 \times$ head width, $1.23 \times$ eye length; OOL $>$ POL in ratio of 29.4:22.0 (LOL not visible in the image); OOL $3.34 \times$ OD; eye $(\mathrm{L}: \mathrm{W}=68.1: 40.2)$ setose; frons with oblique carinae directed towards anterior ocellus; space between carinae smooth with long brown setae; vertex and interocellar area smooth with sparse setigerous punctae; interantennal process rectangular, smooth with a medial longitudinal carina; occiput entirely smooth with sparse setigerous punctae, except for a small patch of dense setigerous foveae medially; gena longitudinally carinate with setigerous punctae; ocelli raised above surface of vertex; antennomeres not clearly visible.

Mesosoma (Figs 17, 18A, C). Cervical pronotal area transversely carinate; mesoscutum (L:W = 104.4: 127.9) laterally smooth with setigerous punctae, anteromedial $2 / 3$ areolate, remaining $1 / 3$ smooth with sparse longitudinal carinae; adjoining this medial patch, longitudinal carinae extend for almost entire length of mesoscutum; mesoscutum laterally smooth with sparse areolae and setigerous punctae; pronotal shoulders with a blunt spine visible when viewed dorsally; lateral pronotal area anteriorly foveate; posteroventral margin of lateral pronotal area extending as a blunt spine; netrion foveate; dorsal mesopleuron with a small triangular rugose patch beneath tegula; mesopleural pit distinct; speculum

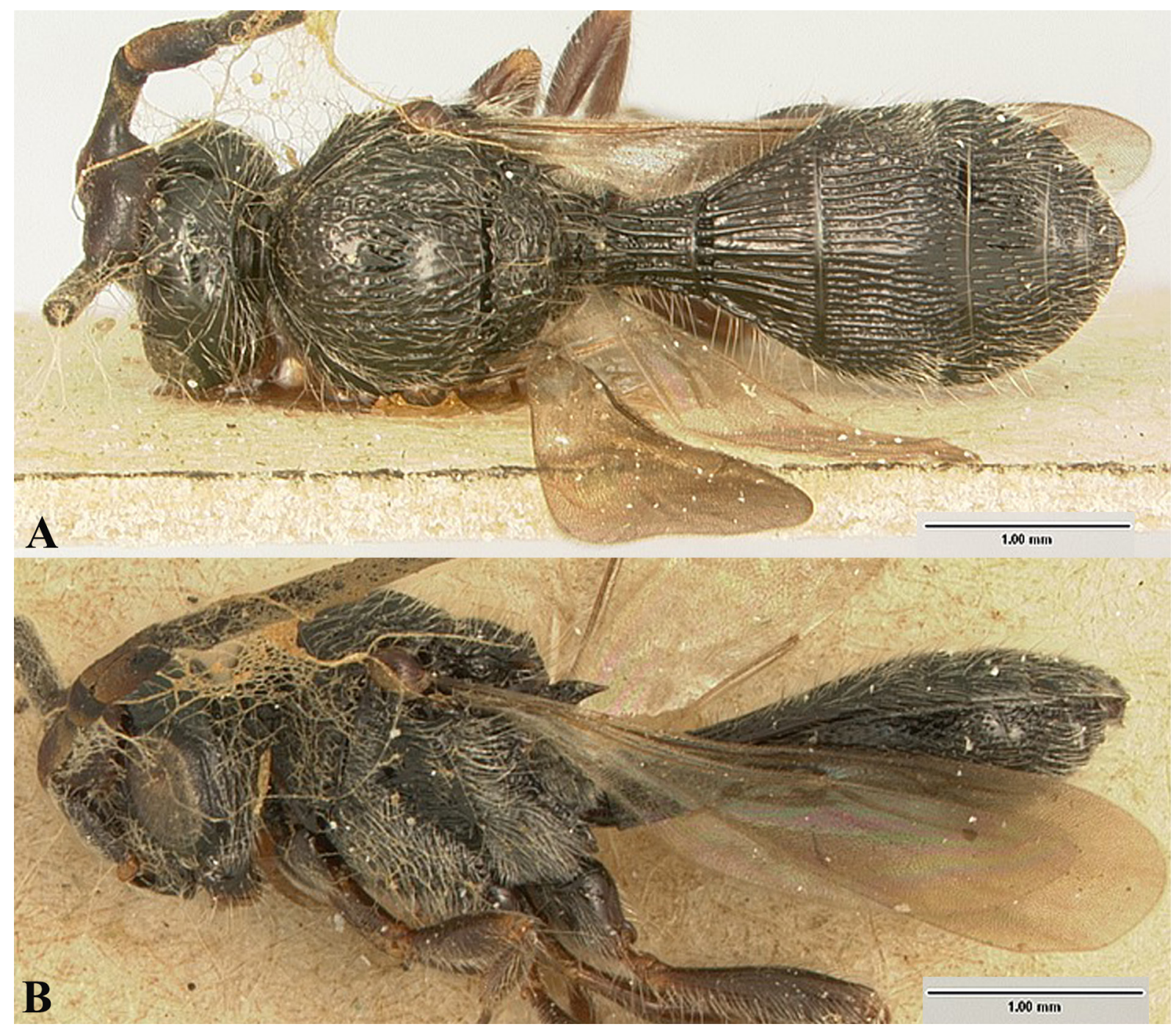

Fig. 17. Odontoscelio striatifrons Kieffer, 1905. Holotype, ô (MCSN). A. Habitus, dorsal view. B. Habitus, lateral view. Photos: N.F. Johnson ${ }^{\circ}$, Ohio State University. 
with weak transverse carinae; mesepimeral sulcus not foveate; posteroventral femoral depression with transverse carinae; episternum and ventral mesopleuron densely setose, obscuring sculpture; metapleuron anteriorly and ventrally densely setose, remainder with large depressions; scutoscutellar sulcus laterally with large foveae; mesoscutellum ( $\mathrm{L}: \mathrm{W}=36.7: 88.2)$ areolate; a median keel present; metascutellum foveate and posteromedially with a triangular spine, metanotal trough foveate; lateral propodeal area laterally densely setose, remainder smooth, except for foveae present along posterior margin; lateral

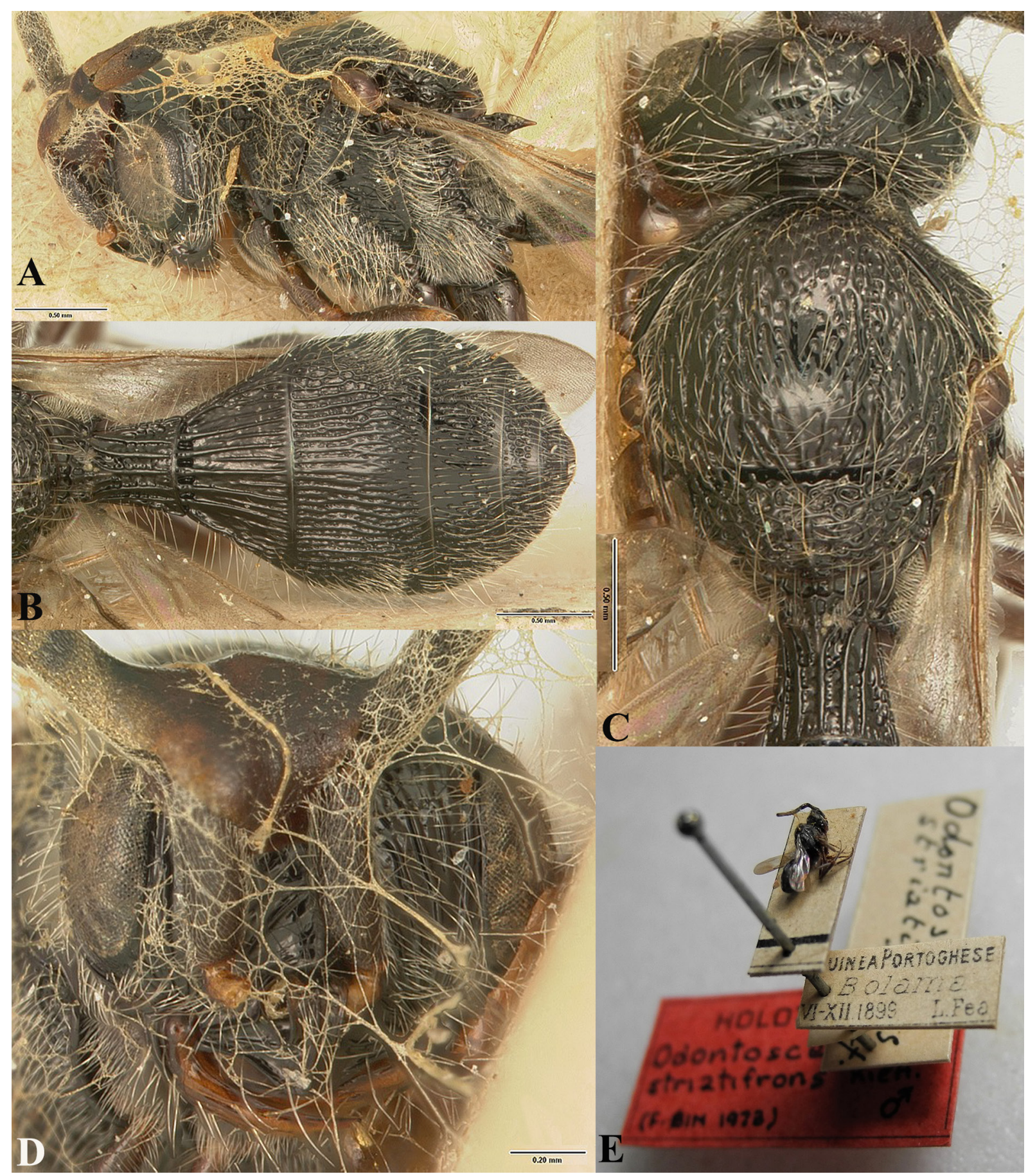

Fig. 18. Odontoscelio striatifrons Kieffer, 1905. Holotype, O (MCSN). A. Head and pleuron. B. Metasoma. C. Head and mesonotum. D. Frons. E. Type label. Photos: A-D: N.F. Johnson ${ }^{\odot}$, Ohio State University; E: Roberto Poggi ${ }^{\circ}, \mathrm{MCSN}$. 
propodeal area extending posterolaterally as a blunt straight spine. Fore wing $(\mathrm{L}: \mathrm{W}=142: 45)$ and hind wing $(\mathrm{L}: \mathrm{W}=122: 30)$ weakly infuscate.

Metasoma (Figs 17, 18B). L:W = 251.2:140.3; T1 longitudinally costate, space between costae weakly foveate; T2 with basal foveae, remainder longitudinally costate, space between costae smooth; T3 longitudinally costate on anterior $4 / 5$, sublaterally areolate, and laterally, posteromedially and posteriorly smooth; space between costae with small foveae medially; T4 medially smooth, setose, remainder with setigerous foveae; T5 and T6 predominantly with setigerous foveae; T7 setose; T1 and T2 with sparse long setae laterally, T3-T6 densely setose laterally; length and width of tergites T1-T7 in ratio of $46.3: 37.8,62.2: 51.2,72.0: 115.8,37.8: 136.5,19.5: 101.2,11.0: 60.9,73.2: 36.5$, respectively.

\section{Remarks}

Kieffer erroneously referred to the holotype as a female specimen in his type information, although later in the description of the genus he stated that females are unknown.

Odontoscelio vikata Veenakumari \& Rajmohana, 2011

Figs 19-20

Odontoscelio vikata Veenakumari \& Rajmohana, 2011a: 87, figs 1-8.

\section{Material examined}

\section{Holotype}

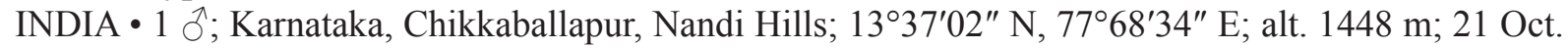
2010, SN; ICAR-NBAII P1.

\section{Paratypes}

INDIA - Karnataka 2 $2 \hat{\jmath}$; same collection data as for holotype but 18 Sep. 2010; ICAR-NBAII

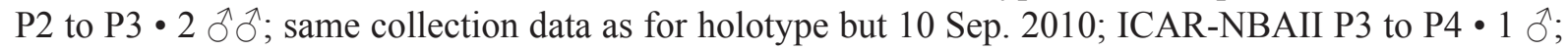

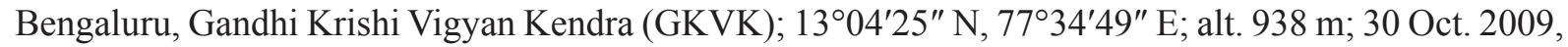
SN; ICAR-NBAII P6.

\section{Other material}

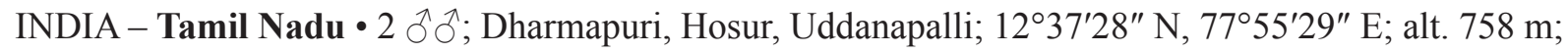

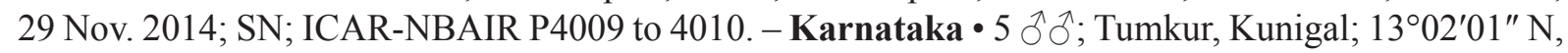

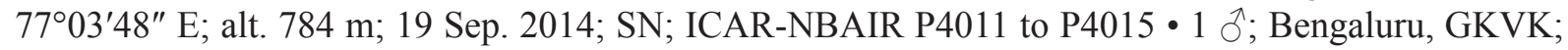
$13^{\circ} 04^{\prime} 25^{\prime \prime} \mathrm{N}, 77^{\circ} 34^{\prime} 49^{\prime \prime}$ E; alt. 938 m; 5 Sep. 2014; SN; ICAR-NBAIR P4016.

\section{Description}

This species was described in detail by Veenakumari et al. (2011a).

\section{Odontoscelio sp. 1}

Figs 21-22

\section{Material examined}

INDIA - Tamil Nadu • 2 $\widehat{\jmath}$; Coimbatore, Tamil Nadu Agriculture University (TNAU); $11^{\circ} 00^{\prime} 55^{\prime \prime}$

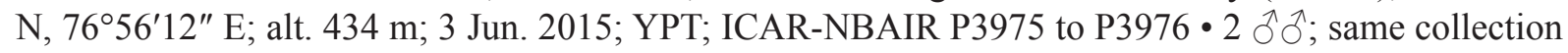
data as for preceding; ICAR-NBAIR P3978 to P3979 • 1 đo ; Tiruchirappalli, Kanapadi; $11^{\circ} 07^{\prime} 02^{\prime \prime}$ N,

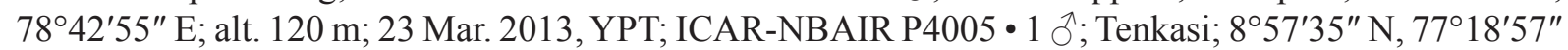
E; alt. 172 m;17 Feb. 2015, YPT; ICAR-NBAIR P4006. 


\section{Remarks}

Odontoscelio sp. 1. is closest to O. agnieleae sp. nov. and Odontoscelio sp. 3, but differs from them in the following characters: T3 with space between costae narrow, posteroventral mesopleuron with indistinct transverse carinae, and foveae on episternum and ventral mesopleuron not arranged in definite rows. In the latter two species the costae on T3 are distantly spaced, the posteroventral mesopleuron has distinct carinae separating depressions, and the foveae on the episternum and ventral mesopleuron are arranged in distinct rows.

A full description and diagnosis will have to await the discovery of females of this species.

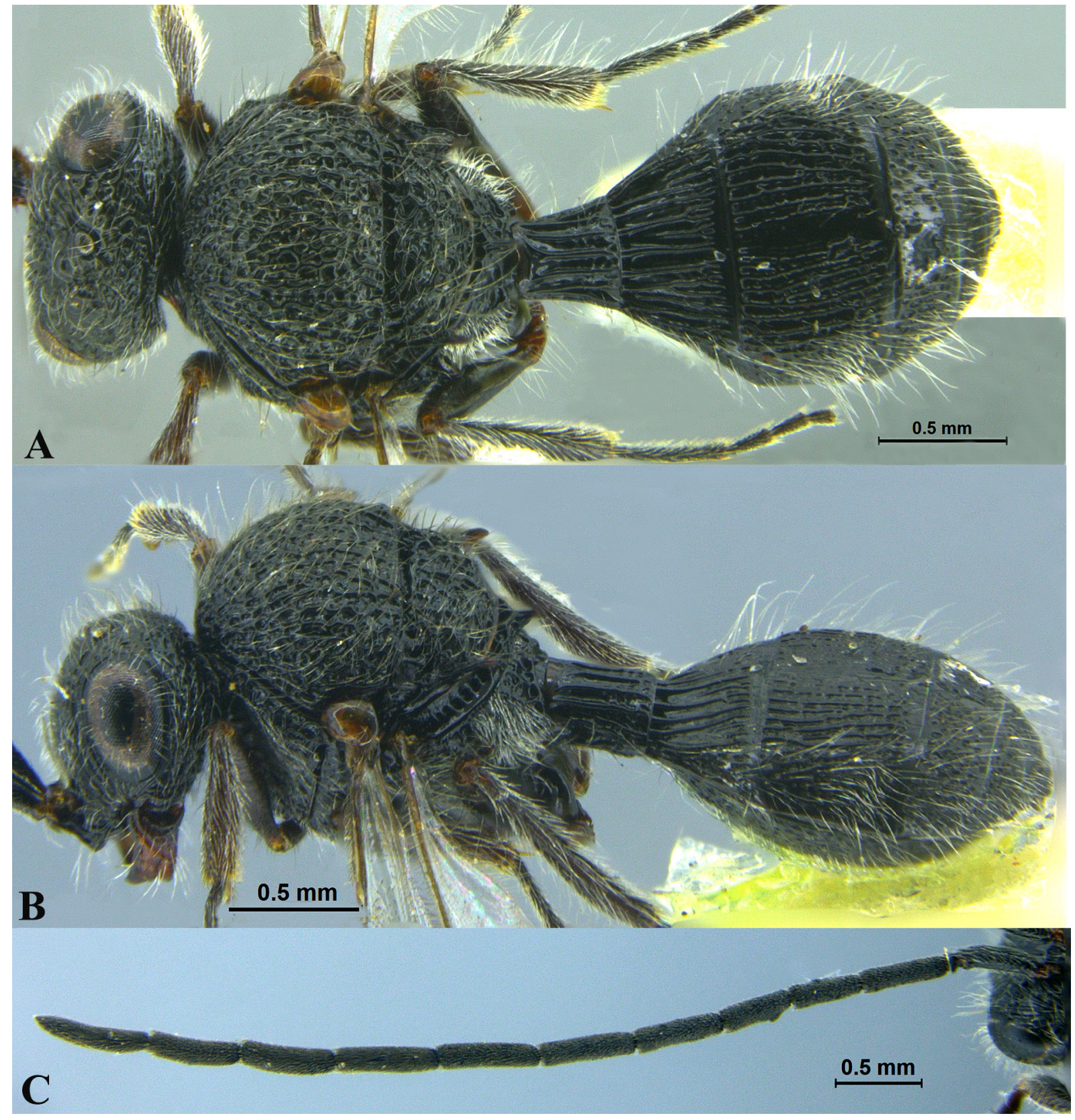

Fig. 19. Odontoscelio vikata Veenakumari \& Rajmohana, 2011. Paratype, ô (ICAR-NBAII P3). A. Habitus, dorsal view. B. Habitus, showing axillular spines. C. Antenna. 
Odontoscelio sp. 2

Figs 23-24

\section{Material examined}

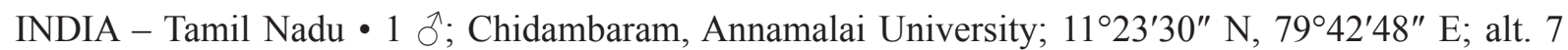
m; 3 Jul. 2016; YPT; ICAR-NBAIR P3982 • 4 ठิ

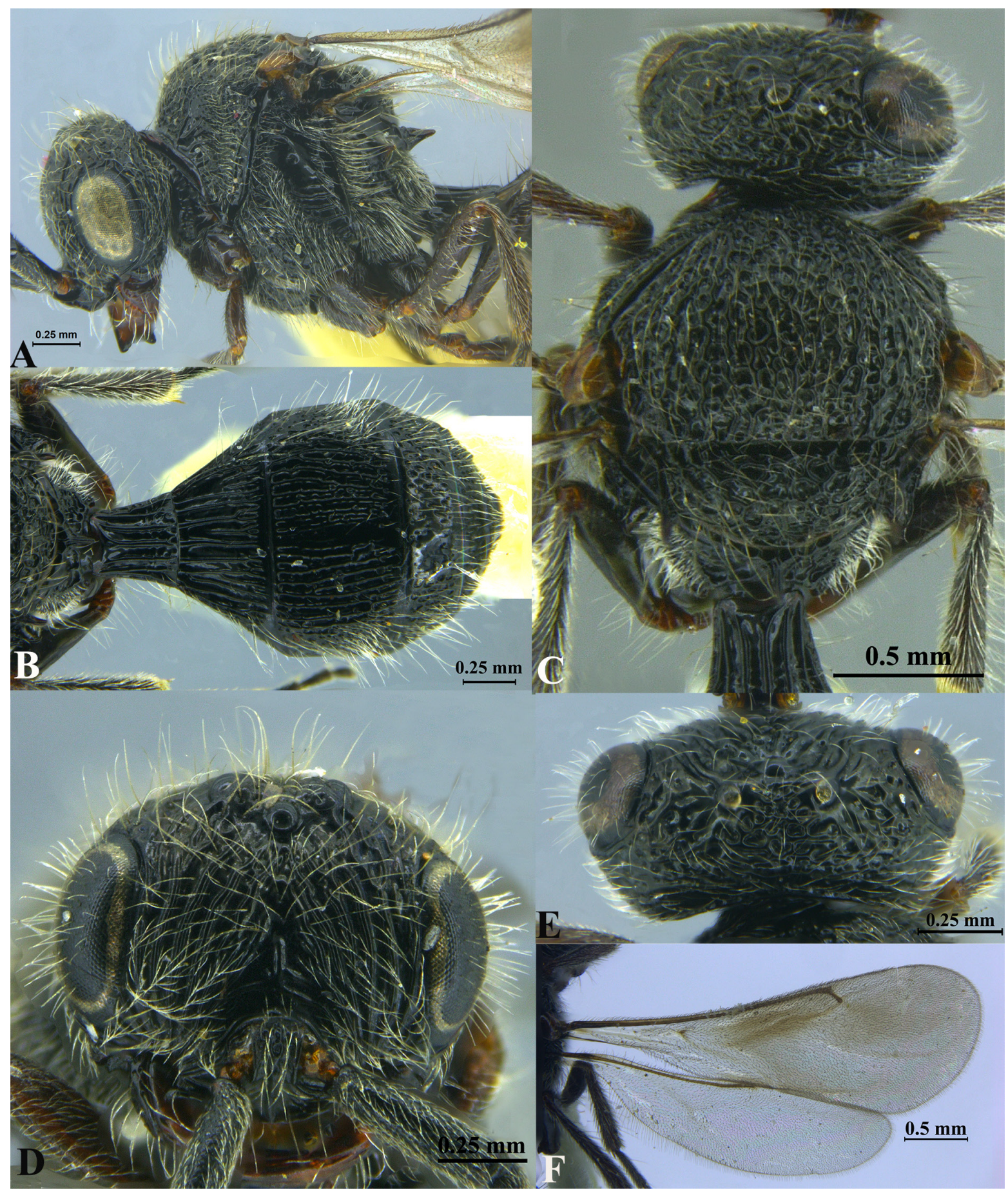

Fig. 20. Odontoscelio vikata Veenakumari \& Rajmohana, 2011. Paratype, ठ̊ (ICAR-NBAII P3). A. Head and pleuron. B. Metasoma. C. Head and mesonotum. D. Frons. E. Vertex. F. Wings. 
2016; ICAR-NBAIR P3983 to P3986 • 4 ổ; same collection data as for preceding; ICAR-NBAIR P3992 to P3995 • 5 ơ ô; same collection data as for preceding but SN; ICAR-NBAIR P3987 to P3991. -

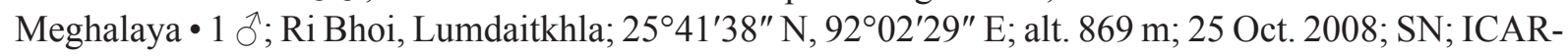

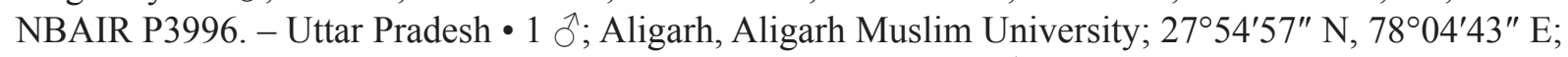
alt. 189 m; 12 Aug. 2006; SN; ICAR-NBAIR P3997. - Kerala • 1 ð’; Kottayam, Kidangoor; 940'55" N, 76³6'28" E; alt. 8 m; 14 Jan. 2012; SN; ICAR-NBAIR P3998.

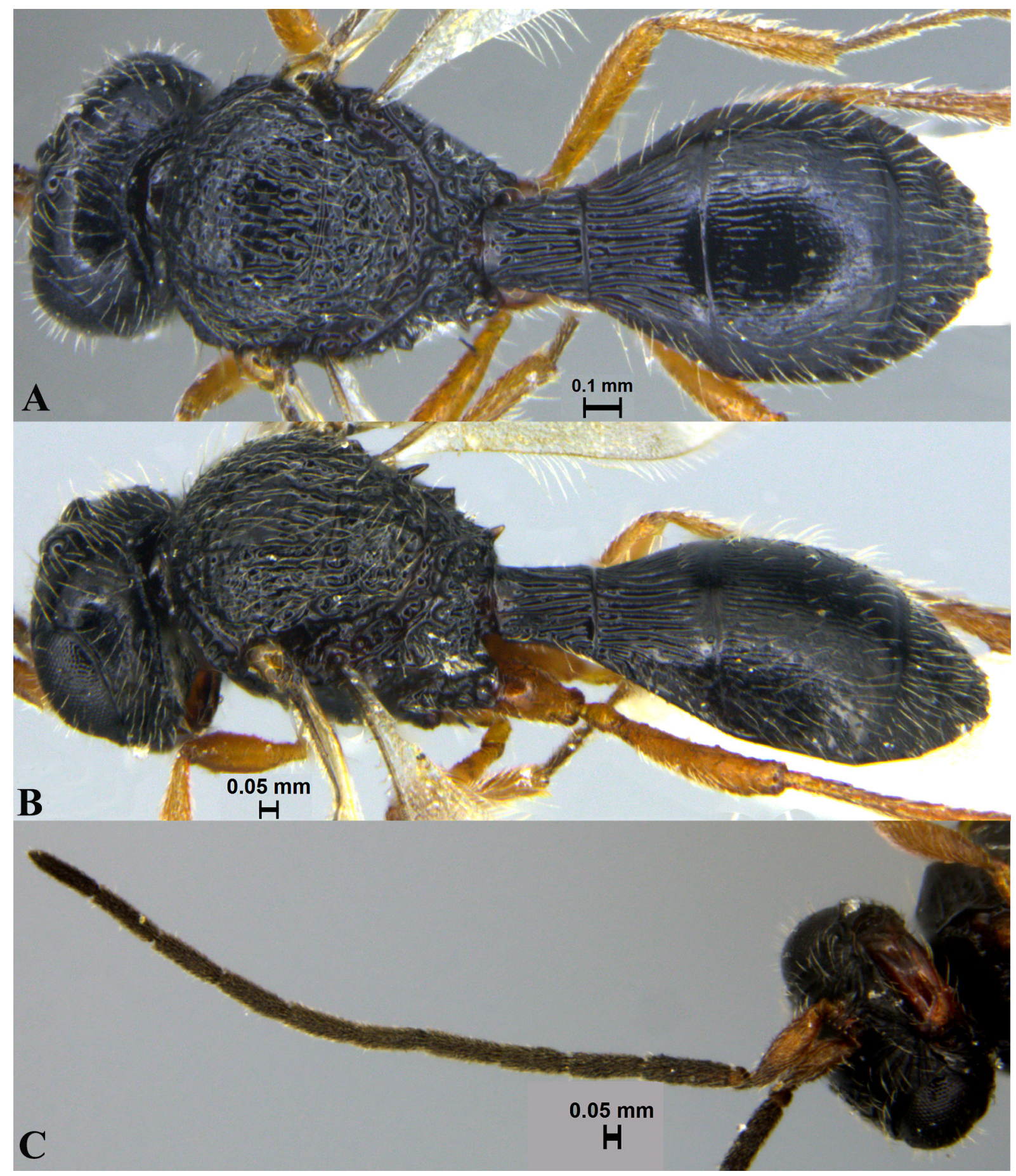

Fig. 21. Odontoscelio sp. 1. §̊ (ICAR-NBAIR P3975). A. Habitus, dorsal view. B. Habitus, showing axillular spines. C. Antenna. 


\section{Remarks}

Odontoscelio sp. 2. is closest to O. agnieleae sp. nov. but differs from it in the following characters: in Odontoscelio sp. 2 the ocelli are placed above the level of the vertex, the eyes are bulging and the mesoscutum is areolate on the anterior half, the posterior half with widely spaced vertical carinae. In O. agnieleae sp. nov. the ocelli are level with the vertex, the eyes are not bulging and the mesoscutum is predominantly areolate.

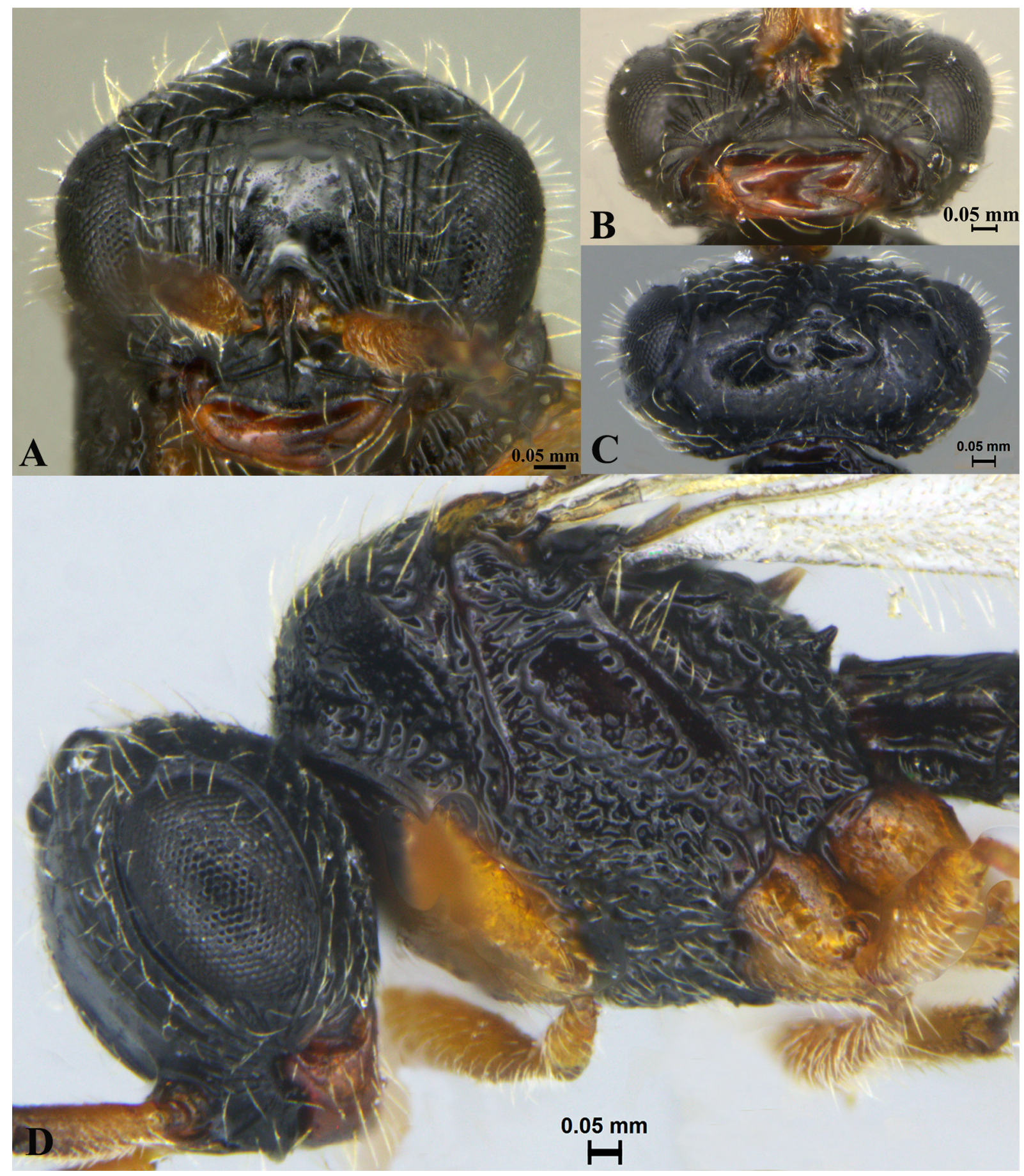

Fig. 22. Odontoscelio sp. 1. ô (ICAR-NBAIR P3975). A. Frons. B. Facial striae. C. Vertex. D. Head and pleuron. 


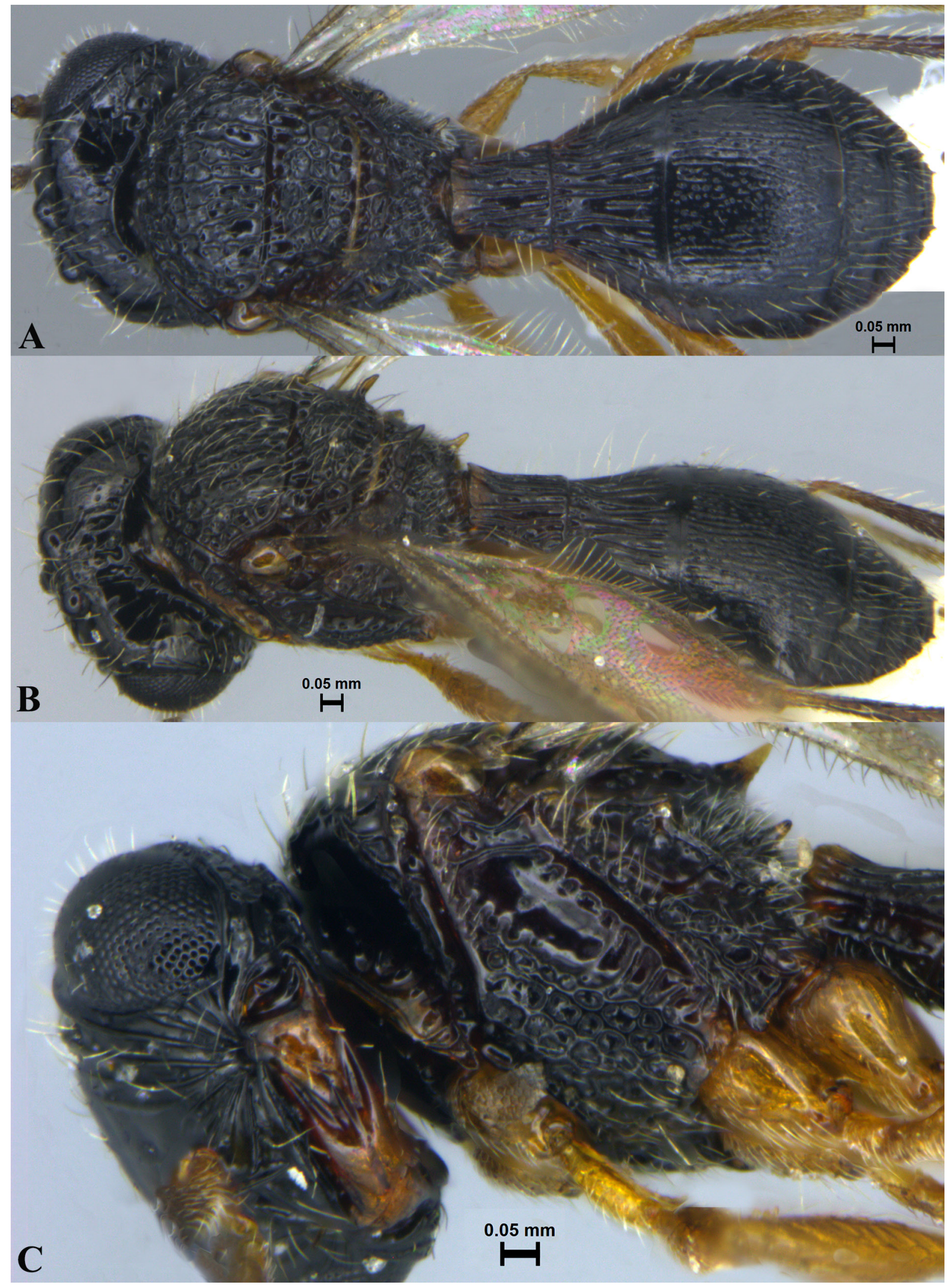

Fig. 23. Odontoscelio sp. 2. đ̊ (ICAR-NBAIR P3982). A. Habitus, dorsal view. B. Habitus, showing axillular spines. C. Head and pleuron. 
The designation of this as a new species awaits the discovery of females.

\section{Odontoscelio sp. 3}

Figs 25-26

\section{Material examined}

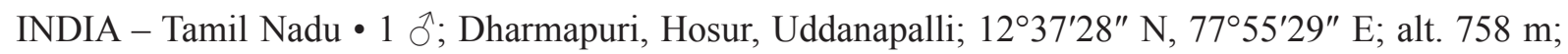
29 Nov. 2014; SN; ICAR-NBAIR P3961 • 1 วิ; same collection data as for preceding; ICAR-NBAIR P3962.

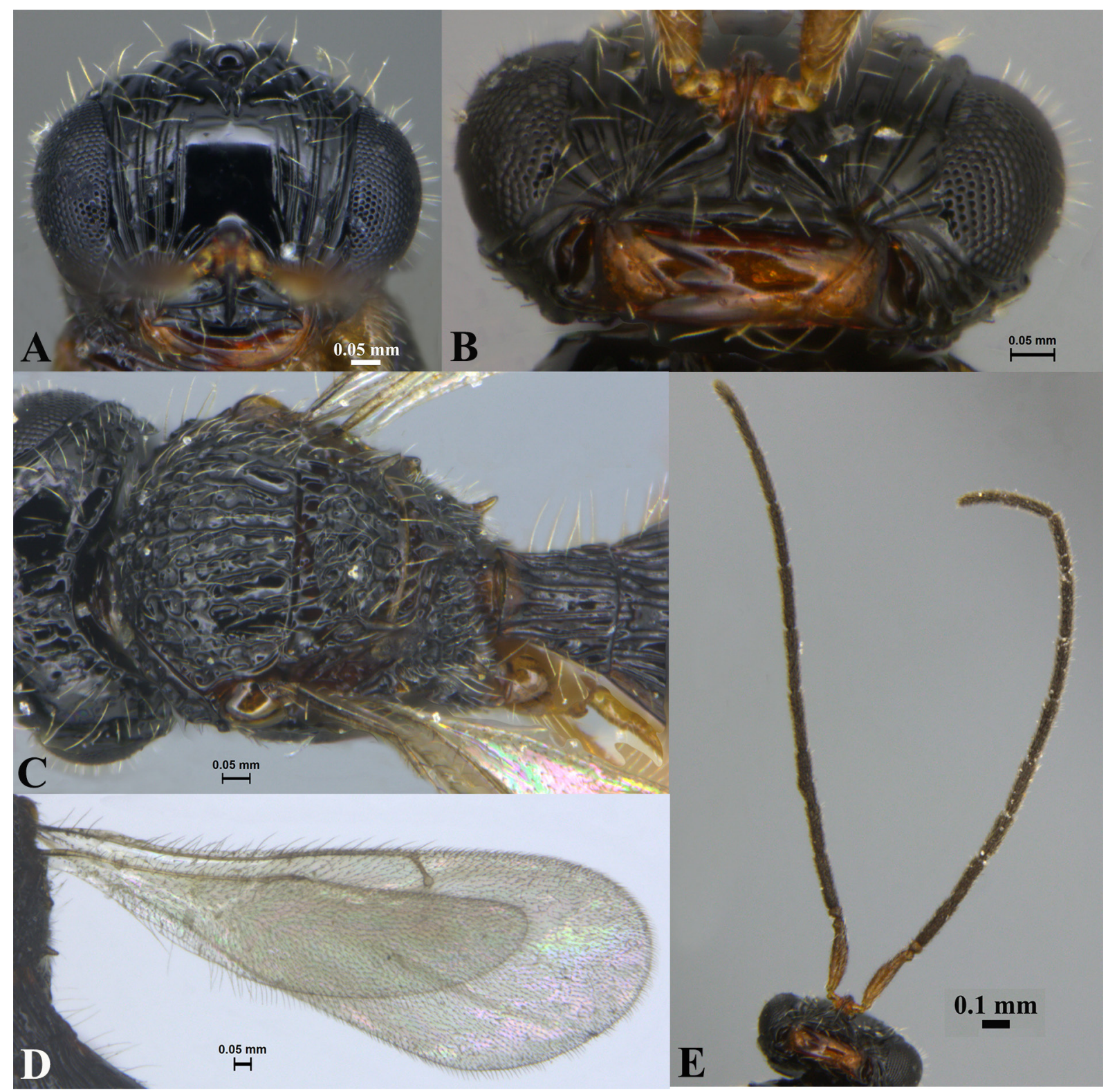

Fig. 24. Odontoscelio sp. 2. đ (ICAR-NBAIR P3982). A. Frons. B. Facial striae. C. Mesonotum. D. Wings. E. Antennae. 


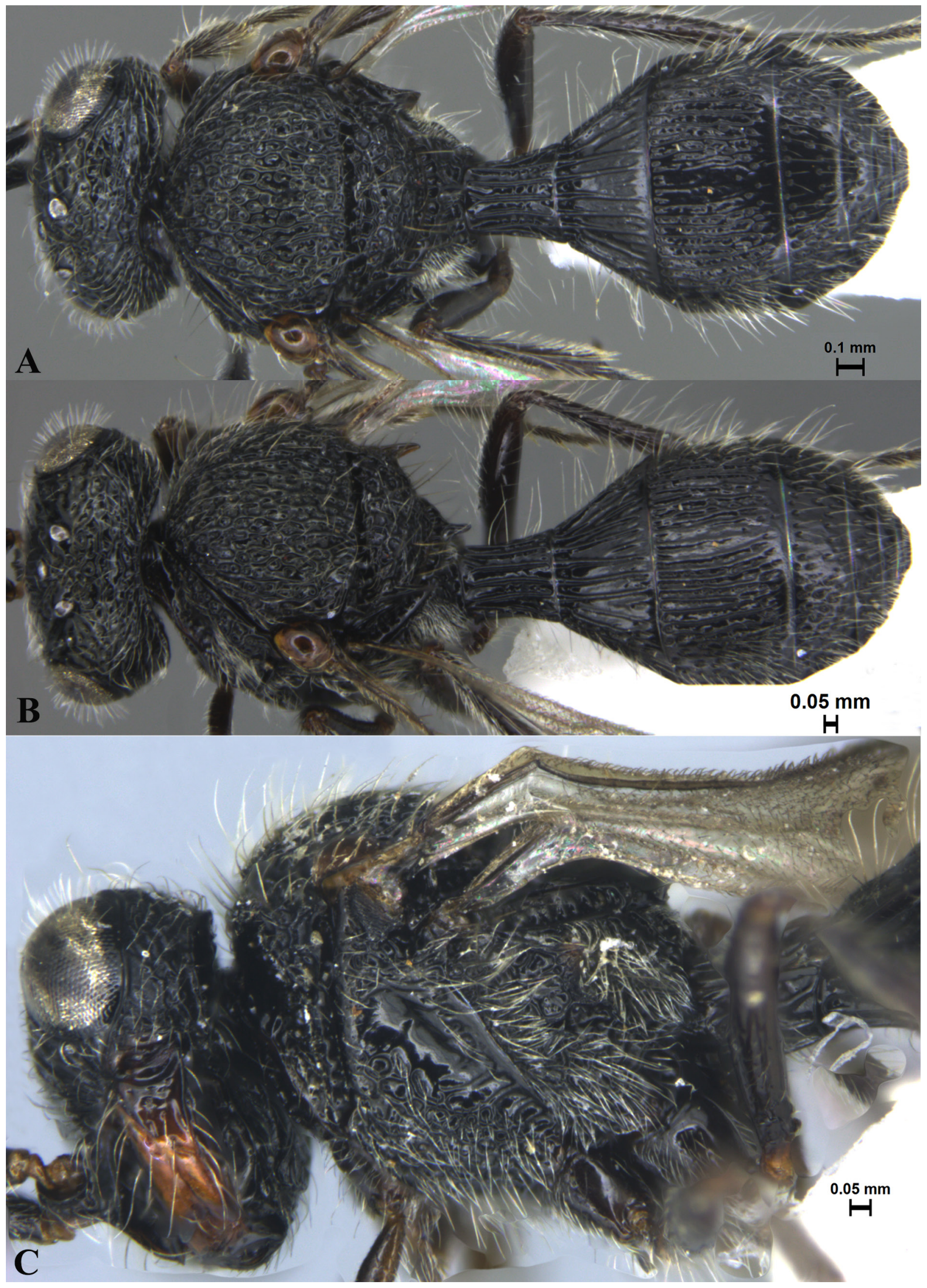

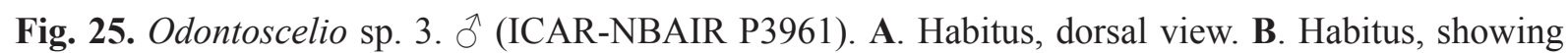
axillular spines. C. Head and pleuron. 


\section{Remarks}

This species is similar to $O$. vikata but differs from it in these characters: in Odontoscelio sp. 3. the occiput is transversely carinate, the carinae on the frons are smooth, the antennomeres are short (A3, A6, A $7<3 \times$ as long as wide). In $O$. vikata the occiput is foveate, the carinae on the frons are ribbed and the antennomeres are elongate (A3, A6, A7 $>3.8 \times$ as long as wide).

As no females were collected this is not currently being described as a new species.

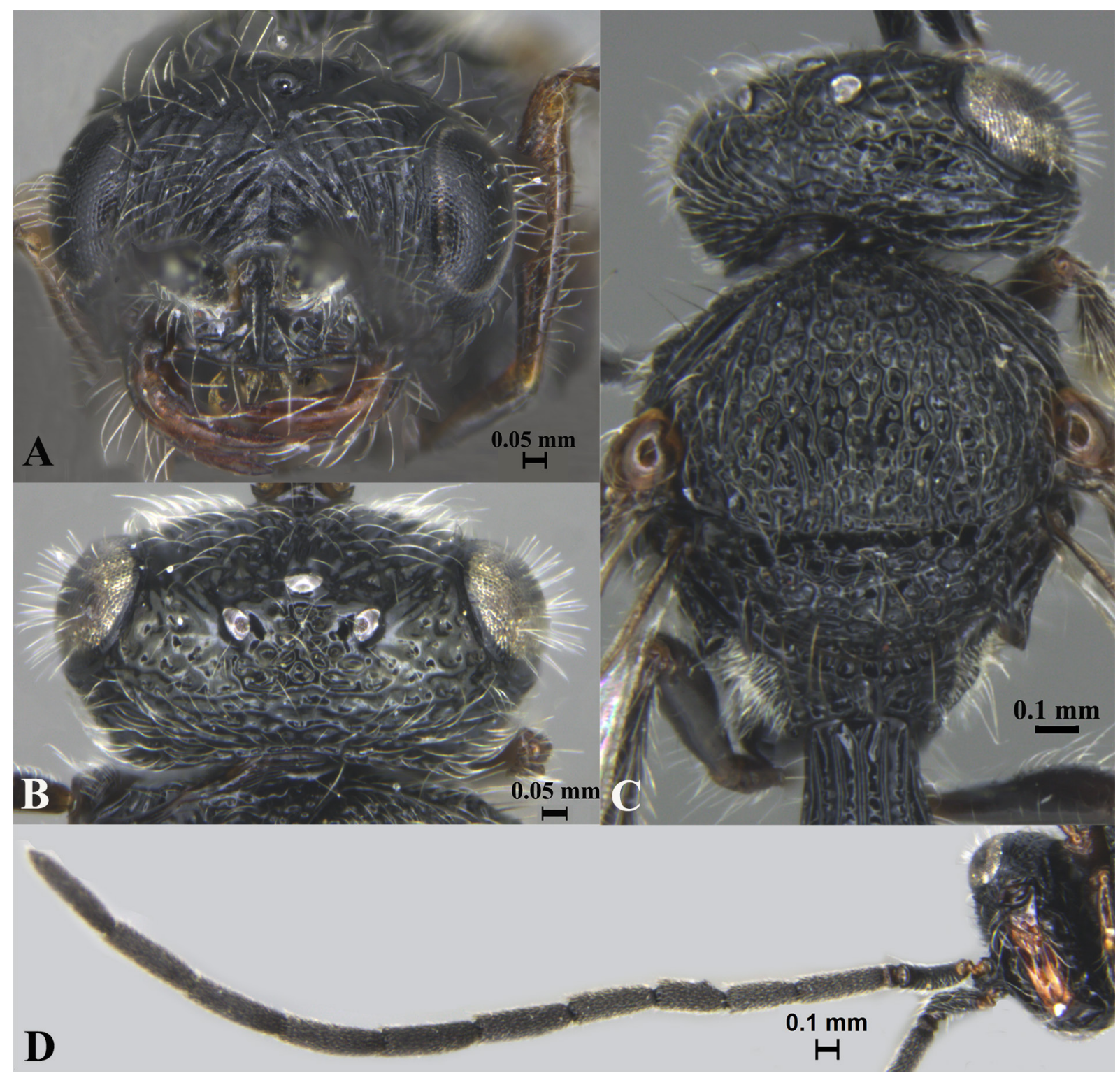

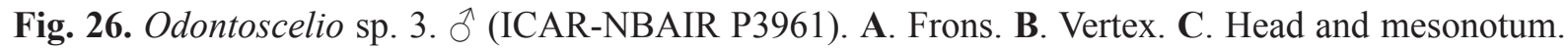
D. Antenna. 


\section{Key to females of Odontoscelio Kieffer, 1905}

1. Frons with semicircular carinae ventral to anterior ocellus (Fig. 3D); medial part of lateral pronotal area transversely carinate (Fig. 4F); metasoma at most $1.4 \times$ as long as wide (Fig. 3A); fore wing entirely infuscate (Fig. 4D)

Odontoscelio spinosus $\mathrm{sp}$. nov.

- Frons with longitudinal or oblique carinae with space between these carinae smooth (Figs 2A, $6 \mathrm{D}$ ), if semicircular carinae present, then confined to only above the interantennal process with a smooth area followed by areolate rugose sculpture above it (Fig. 10D); lateral pronotal area medially smooth (Figs 1C, 6A, 10A); metasoma at least $1.9 \times$ as long as wide (Figs 1A, $5 \mathrm{~A}, 9 \mathrm{~A}$ ); fore wing hyaline or only partially infuscate (Figs 2C, 5A, 9B)

2. Vertex areolate (Figs 9A, 10E); frons dorsally areolate with setigerous punctae, smooth medially, with semicircular carinae above interantennal process, remainder with oblique carinae radiating towards centre, interspersed with setigerous punctae (Fig. 10D); T3 predominantly costate except for a small smooth patch posteromedially (Fig. 10B); OOL $3.9 \times$ OD (Fig. 9A); femoral depression transversely carinate (Figs 9B, 10A)

Odontoscelio caelebs (Nixon, 1936)

- Vertex predominantly smooth (Figs 2D, 5A, 6C-D); frons entirely smooth with setigerous punctae except for longitudinal carinae laterally (Figs 2A, 6D); T3 either punctate medially or costate only on anterior half (Figs 1A, 5A, 6B); OOL at most $3.3 \times$ OD (Figs 2D, 6C-D); femoral depression partially smooth (Figs 1C, 6A)

3. Carinae on lateral frons longitudinal and dense (Fig. 2A); A3 and A4 subequal in length (Fig. 2B); pronotal shoulder without lateral spine when viewed dorsally (Fig. 2E); mesoscutum areolate (Figs 1A, 2E); posteroventral portion of femoral depression with elongate depressions (Fig. 1C); mesopleuron and metapleuron ventrally sparsely setose; T1 with a distinct horn (Fig. 1A-C); T3 medially punctate, submedially and sublaterally longitudinally costate with foveae between costae; lateral teeth on T6 small and glabrous (Fig. 1A-B)

Odontoscelio agnieleae sp. nov.

- Carinae on lateral frons oblique, directed towards centre and sparse (Fig. 6D); A3 more than $2 \times$ A4 in length (Fig. 6D); pronotal shoulder with a lateral spine when viewed dorsally (Fig. 6C); mesoscutum with longitudinal carinae posteriorly (Fig. 6C); femoral depression with several transverse carinae ventral to mesopleural pit (Fig. 6A); mesopleuron and metapleuron ventrally densely setose; T1 without horn; T3 medially longitudinally costate on anterior half, posterior half smooth with setigerous punctae; T6 with two large, densely setose lateral teeth and a median lobe (Figs 5A-B, 6B)

Odontoscelio apperti (Risbec, 1953)

\section{Key to males of Odontoscelio Kieffer, 1905}

1. T3 medially with longitudinal costae for at least half the length of the tergite (Figs 7A, 8B, 11A, 12B, 17A, 18B, 19A-B, 20B)

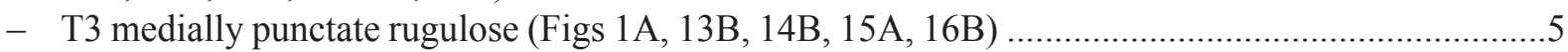

2. Vertex and occiput predominantly smooth with setigerous punctae (Figs 17A, 18C); mesoscutum laterally with effaced sculpture and setigerous punctae (Figs 17A, 18C); lateral propodeal area predominantly smooth except for foveae on posterior margin (Fig. 18C); T3 sublaterally areolate (Figs 17A, 18B)

Odontoscelio striatifrons Kieffer, 1905

- Vertex and occiput sculptured (Figs 8A, C, 11A, 20C, E); mesoscutum laterally either foveate or carinate (Figs 8C, 12C, 20C); lateral propodeal area sculptured (Figs 8C, 12C, 20C); T3 sublaterally with variable sculpture (Figs 7A, 8B, 11A, 12B, 19A, 20B)

3. Facial striae on frons do not intersect medially (Fig. 20D); frons with central keel (Fig. 20D); POL $>$ OOL (Fig. 20E); mesoscutum areolate (Fig. 20C) 
- Facial striae on frons intersect medially; frons without central keel (Figs 8E, 12D); OOL > POL (Figs 8C-E, 12D); mesoscutum with several longitudinal carinae in addition to foveae (Figs 8C, 12C)

4. Dorsal carinae on frons beneath anterior ocellus converge medially into a smooth area (Fig. $8 \mathrm{E}$ ); semicircular carinae present above interantennal process (Fig. 8E); A1 short, at most $3 \times$ as long as wide (Fig. 8E); mesoscutum $2 \times$ as long as mesoscutellum (Fig. 8C); medial keel of mesoscutellum present (Fig. 8C); femoral depression ventral to mesopleural pit with more than eight transverse carinae (Fig. 8A); metascutellar spine short and basally wide (Fig. 8B-C); T3 medially longitudinally carinate only on anterior half; metasoma ovoid, $1.6 \times$ as long as wide (Fig. 8B)

Odontoscelio brevicephala (Risbec, 1956)

- Converging oblique carinae on frons interconnected with longitudinal carinae medially (Fig. 12A); carinae aboveinterantennal process oblique (Fig. 12D);A1 long, at least $3.7 \times$ as long as wide(Fig. 12D); mesoscutum at most $1.3 \times$ as long as mesoscutellum; medial keel absent on mesoscutellum (Fig. 12C); femoral depression ventral to mesopleural pit with three transverse carinae (Fig. 12A); metascutellar spine narrow and elongate (Figs 11B, 12A); T3 medially longitudinally carinate along entire length except for a narrow smooth posterior margin; metasoma oblong, $>2 \times$ as long as wide (Fig. 12B)

Odontoscelio echion (Nixon, 1936)

5. Vertex and occiput smooth (Fig. 1A); mesoscutum areolate (Fig. 1A); carinae on frons longitudinal, not bending towards anterior ocellus (Fig. 2A); LOL very short, at most $0.1 \times$ OOL (Fig. 2D)

Odontoscelio agnieleae sp. nov.

- Vertex and occiput sculptured (Figs 13B, 16A, C); mesoscutum with closely placed longitudinal carinae (Figs 13B, 16C); carinae on frons oblique, directed towards anterior ocellus (Figs 14D, 16D); LOL long, at least $0.4 \times$ OOL

6. Frons entirely smooth medially from interantennal process to anterior ocellus, except for a short longitudinal carina beneath anterior ocellus (Fig. 14D); suprahumeral sulcus foveate (Fig. 13C); vertex smooth with sparse setigerous punctae (Fig. 13A); mesoscutellum anteromedially with a smooth patch (Fig. 14C); entire lateral propodeal area with short setae and indistinct foveae; lateral propodeal carina absent (Fig. 14C); ventral mesopleuron and anterior metapleuron with sparse, short setae (Fig. 14A); T3 medially densely foveate (Fig. 14B); antennomeres elongate and with sparse setae (Fig. 13D); coxae brown (Fig. 13C)

Odontoscelio laticephalus (Risbec, 1950)

- Frons sculptured medially, except for a small, smooth patch above interantennal process, no longitudinal carina present beneath anterior ocellus (Fig. 16A); suprahumeral sulcus not foveate (Fig. 16A); vertex areolate with sparse carinae (Fig. 16D); entire mesoscutellum areolate; lateral propodeal area laterally with dense setae, remainder with well defined foveae; lateral propodeal carina present (Fig. 16C); ventral mesopleuron and anterior metapleuron with dense, long setae (Fig. 16A); T3 medially smooth with sparse setigerous punctae (Fig. 16B); antennomeres short and stout, with short, dense setae (Fig. 15B); coxae black (Fig. 16A) ...

Odontoscelio pluto (Nixon, 1936)

\section{Acknowledgements}

The authors are grateful to the Director of NBAIR, Bengaluru for providing facilities. We are extremely grateful to Agnièle Touret-Alby, Curator of the collection, Entomology - Hymenoptera, Muséum national d'histoire naturelle, Paris; Dr N.F. Johnson, Ohio State University, Columbus, Ohio, USA; David B. Notton, Natural History Museum, London, UK; and Dr Roberto Poggi, Honorary Curator, Museo Civico di Storia Naturale "Giacomo Doria", Genova, Italy for the images of the type specimens. We also thank the referees for their valuable suggestions. We thank B.L. Lakshmi, V. Shashikala, 
B. Vinod and Roopa for their support both in the field and in the laboratory. Thanks are also due to Dr N.F. Johnson for the Hymenoptera online database for literature support.

\section{References}

Bin F. 1974. The types of Scelionidae [Hymenoptera: Proctotrupoidea] in some Italian collections (Museum of Genoa and Florence, Institute of Portici). Entomophaga 19: 453-466. https://doi.org/10.1007/BF02372781

Harris R.A. 1979. A glossary of surface sculpturing. Occasional Papers in Entomology 28: 1-31. https://doi.org/10.5281/zenodo.26215

Johnson N.F. 1992. Catalog of world Proctotrupoidea excluding Platygastridae. Memoirs of the American Entomological Institute 51: 1-825. https://doi.org/10.5281/zenodo.23657

Kieffer J.J. 1905. Nouveaux proctotrypides exotiques conserves au Musée Civique de Gênes. Annali del Museo Civico di Storia Naturale "Giacomo Doria" (Genova) 2 (2): 9-39.

https://doi.org/10.5281/zenodo.23763

Kieffer J.J. 1926. Scelionidae. In: Kieffer J.J. (ed.) Das Tierreich, volume 48. Walter de Gruyter \& Co., Berlin.

Masner L. 1965. The types of Proctotrupoidea (Hymenoptera) in the British Museum (Natural History) and in the Hope Department of Entomology, Oxford. Bulletin of British Museum (Natural History), Entomology Supplement 1: 1-154. Available from https://www.biodiversitylibrary.org/page/40871778 [accessed 15 Feb. 2021].

Masner L. 1976. Revisionary notes and keys to world genera of Scelionidae (Hymenoptera: Proctotrupoidea). Memoirs of the Entomological Society of Canada 108 (S97): 1-87.

https://doi.org/10.4039/entm10897fv

Masner L. 1980. Key to genera of Scelionidae of the Holarctic region, with descriptions of new genera and species (Hymenoptera: Proctotrupoidea). Memoirs of the Entomological Society of Canada 112 (S113): 1-54. https://doi.org/10.4039/entm112113fv

Mikó I., Vilhelmsen L., Johnson N.F., Masner L. \& Pénzes Z. 2007. Skeleto-musculature of Scelionidae (Hymenoptera: Platygastroidea) head and mesosoma. Zootaxa 1571 (1): 1-78.

https://doi.org/10.11646/zootaxa.1571.1.1

Mikó I., Masner L. \& Deans A.R. 2010. World revision of Xenomerus Walker (Hymenoptera: Platygastroidea, Platygastridae). Zootaxa 2708 (1): 1-73. https://doi.org/10.11646/zootaxa.2708.1.1

Mukerjee M.K. 1993. On a collection of Scelionidae (Proctotrupoidea: Hymenoptera) from Garhwal Himalayas, India. Hexapoda 5 (1): 75-105.

Nixon G.E.J. 1936. The African species of Teleasinae (Hym., Proctotrupoidea, Fam. Scelionidae). Annals and Magazine of Natural History (10) 17 (97): 114-141.

https://doi.org/10.1080/03745481.1936.10801393

Risbec J. 1950. Contribution à l'étude des Proctotrupidae (Serphiidae). Proctotrupidés de la Section technique d'Agriculture tropicale (A.O.F.) et proctotrupidés du Muséum national d'Histoire naturelle (Afrique et Colonies francaises). In: Risbec J. (ed.) Travaux du Laboratoire d'Entomologie du Secteur soudanais de Recherches agronomiques, Gouvernement générale de l'Afrique occidentale française: $1-639$.

Risbec J. 1953. Chalcidoïdes et proctotrupoïdes de l'Afrique occidentale française ( $2^{\text {nd }}$ Supplement). Bulletin de l'Institut français d'Afrique noire 15: 548-609. 
Risbec J. 1956. Scelioninae de Madagascar (Telenomini, Teleasini, Baeini). Bulletin de la Société zoologique de France 80: 364-374. https://doi.org/10.5281/zenodo.24044

Talamas E.J., Miko I. \& Copeland R.S. 2016. Revision of Dvivarnus (Scelionidae, Teleasinae). Journal of Hymenoptera Research 49: 1-23. https://doi.org/10.3897/JHR.49.7714

Various contributors. 2020. Hymenoptera online (HOL).

Available from https://mbd-p.asc.ohio-state.edu/hol/ [accessed 15 Feb. 2020].

Veenakumari K., Rajmohana K. \& Mohanraj P. 2011a. Description of Odontoscelio vikata sp. nov. (Hymenoptera: Platygastroidea: Platygastridae) from India. Hexapoda 18 (2): 87-92.

Veenakumari K., Rajmohana K., Manickavasagam S. \& Mohanraj P. 2011b. On a new genus of Teleasinae (Hymenoptera: Platygastridae) from India. Biosystematica 5: 39-46.

Manuscript received: 17 July 2020

Manuscript accepted: 10 December 2020

Published on: 15 March 2021

Topic editor: Nesrine Akkari

Desk editor: Danny Eibye-Jacobsen

Printed versions of all papers are also deposited in the libraries of the institutes that are members of the EJT consortium: Muséum national d'histoire naturelle, Paris, France; Meise Botanic Garden, Belgium; Royal Museum for Central Africa, Tervuren, Belgium; Royal Belgian Institute of Natural Sciences, Brussels, Belgium; Natural History Museum of Denmark, Copenhagen, Denmark; Naturalis Biodiversity Center, Leiden, the Netherlands; Museo Nacional de Ciencias Naturales-CSIC, Madrid, Spain; Real Jardín Botánico de Madrid CSIC, Spain; Zoological Research Museum Alexander Koenig, Bonn, Germany; National Museum, Prague, Czech Republic. 